\title{
Lactate Mediates the Effects of Exercise on Learning and Memory through SIRT1-Dependent Activation of Hippocampal Brain-Derived Neurotrophic Factor (BDNF)
}

\author{
Lauretta El Hayek, ${ }^{1}$ Mohamad Khalifeh, ${ }^{1}$ Victor Zibara, ${ }^{1}$-Rawad Abi Assaad, ${ }^{1}$ @ Nancy Emmanuel, ${ }^{1}$ Nabil Karnib, ${ }^{1}$ \\ Rim El-Ghandour, ${ }^{1}$ Patrick Nasrallah, ${ }^{1}$ Maria Bilen, ${ }^{1}$ Pascale Ibrahim, ${ }^{1}$ Joe Younes, ${ }^{1}$ Edwina Abou Haidar, ${ }^{1}$ \\ Nour Barmo, ${ }^{1}$ Vanessa Jabre, ${ }^{1}$ Joseph S. Stephan, ${ }^{2}$ and ${ }^{\circ}$ Sama F. Sleiman ${ }^{1}$ \\ ${ }^{1}$ Molecular Biology Program, Department of Natural Sciences, and ${ }^{2}$ School of Medicine, Lebanese American University, Byblos, Lebanon
}

Exercise promotes learning and memory formation. These effects depend on increases in hippocampal BDNF, a growth factor associated with cognitive improvement and the alleviation of depression symptoms. Identifying molecules that are produced during exercise and that mediate hippocampal $B d n f$ expression will allow us to harness the therapeutic potential of exercise. Here, we report that an endogenous molecule produced during exercise in male mice induces the Mus musculus Bdnf gene and promotes learning and memory formation. The metabolite lactate, which is released during exercise by the muscles, crosses the blood-brain barrier and induces $B d n f$ expression and TRKB signaling in the hippocampus. Indeed, we find that lactate-dependent increases in BDNF are associated with improved spatial learning and memory retention. The action of lactate is dependent on the activation of the Sirtuin1 deacetylase. SIRT1 increases the levels of the transcriptional coactivator PGCla and the secreted molecule FNDC5, known to mediate Bdnf expression. These results reveal an endogenous mechanism to explain how physical exercise leads to the induction of BDNF, and identify lactate as a potential endogenous molecule that may have therapeutic value for CNS diseases in which BDNF signaling is disrupted.

Key words: BDNF; exercise; learning; memory formation; PGC1a; Sirt1

\section{Significance Statement}

It is established that exercise promotes learning and memory formation and alleviates the symptoms of depression. These effects are mediated through inducing $B d n f$ expression and signaling in the hippocampus. Understanding how exercise induces $B d n f$ and identifying the molecules that mediate this induction will allow us to design therapeutic strategies that can mimic the effects of exercise on the brain, especially for patients with CNS disorders characterized by a decrease in $B d n f$ expression and who cannot exercise because of their conditions. We identify lactate as an endogenous metabolite that is produced during exercise, crosses the blood-brain barrier and promotes hippocampal dependent learning and memory in a BDNF-dependent manner. Our work identifies lactate as a component of the "exercise pill."

\section{Introduction}

Exercise attenuates the symptoms of neurodegenerative diseases, such as Alzheimer's and Parkinson's diseases (Adlard et al., 2005b; Nichol et al., 2007; Tajiri et al., 2010; Real et al., 2013) as

Received July 2, 2018; revised Dec. 14, 2018; accepted Jan. 13, 2019.

Author contributions: J.S.S. and S.F.S. edited the paper; S.F.S. wrote the first draft of the paper. J.S.S. and S.F.S. designed research; L.E.H., M.K., V.Z., R.A.A., N.E., N.K., R.E.-G., P.N., M.B., P.I, E.A.H., J.Y., N.B., V.J., and S.F.S. performed research; J.S.S. and S.F.S. contributed unpublished reagents/analytic tools; L.E.H., V.Z., R.A.A., N.E., and S.F.S. analyzed data; J.S.S. and S.F.S. wrote the paper.

This work was supported by the Lebanese American University School of Arts and Sciences and Graduate Research Fund. The TRKb and p-TRKb antibodies are a kind gift from Dr. Moses V. Chao.

The authors declare no competing financial interests.

Correspondence should be addressed to Sama F. Sleiman at sama.sleiman01@lau.edu.lb.

https://doi.org/10.1523/JNEUROSCl.1661-18.2019

Copyright $\odot 2019$ the authors $\quad 0270-6474 / 19 / 392369-14 \$ 15.00 / 0$ well as relieves the symptoms of depression (Russo-Neustadt et al., 2000; Duman et al., 2008). Exercise mediates these beneficial responses by inducing neurogenesis (van Praag et al., 1999) and improving learning and memory formation (Vaynman et al., 2004, 2006; Berchtold et al., 2010). The positive changes observed in the brain after exercise are mediated by the induction of BDNF expression in the hippocampus (Neeper et al., 1995; Oliff et al., 1998; Tong et al., 2001; Berchtold et al., 2005) and the activation of its tropomyosin kinase receptor B (TRKB) receptor (Vaynman et al., 2004; Real et al., 2013; Parrini et al., 2017). Indeed, blocking BDNF signaling in the hippocampus attenuates exercise-induced learning and memory formation (Vaynman et al., 2004; GarcíaMesa et al., 2014; Kim and Leem, 2016).

BDNF is highly expressed in the brain where it regulates neuronal survival, growth, and differentiation during development. 
BDNF also mediates spine formation and neuronal plasticity as well as promotes learning and memory (Mitre et al., 2017). Indeed, alterations in BDNF/TRKB signaling are observed in a variety of CNS disorders (Gupta et al., 2013; Mitre et al., 2017). Considering the important role that BDNF plays in mediating brain health, identifying novel molecules and pathways that induce BDNF is of immediate therapeutic relevance.

It has long been established that exercise increases BDNF levels and signaling in the hippocampus to enhance learning and memory formation and ameliorate the symptoms of diseases (Cotman et al., 2007; Wrann et al., 2013; Sleiman et al., 2016); however, the molecular pathways responsible for the exercisemediated BDNF induction have been elusive. There has been some recent progress in elucidating these pathways. We have shown that a ketone body, $\beta$-hydroxybutyrate (DBHB) produced in the liver during exercise, is released into the blood where it accumulates in the hippocampus and induces $B d n f$ expression by acting as a direct Class I histone deacetylase (HDAC) inhibitor. By inhibiting HDAC2 and HDAC3 and preventing their recruitment to the $B d n f$ promoter I, DBHB induces $B d n f$ expression and mediates synaptic plasticity (Sleiman et al., 2016). Another mechanism by which exercise induces hippocampal $B d n f$ expression results from the induction of the transcriptional coactivator PGCla and the estrogen-related receptor ERRa. This transcriptional activating complex induces the expression of the myokine gene Fndc5. FNDC5 activates hippocampal Bdnf expression (Wrann et al., 2013). It is not yet known how FNDC5, a protein that is cleaved and secreted, is capable of activating hippocampal $B d n f$ gene expression to promote learning and memory formation.

In this work, we endeavored to identify novel exerciseproduced molecules that could induce hippocampal $B d n f$ gene expression. Identifying such endogenous "exercise factors" transmitted from peripheral organs through the blood to the CNS where they can mediate brain health may be crucial for harnessing the full therapeutic potential of exercise.

One molecule that is released after exercise by the muscle is lactate. Lactate is released into the blood and taken up by the liver, where it is converted back to pyruvate, and later to glucose or glycogen depending on cellular needs. Lactate also crosses the blood-brain barrier (BBB) via endothelial monocarboxylate transporters (MCTs) (Pierre and Pellerin, 2005; E et al., 2013) and serves as an energy source for the brain (Quistorff et al., 2008) and as a neuroprotective factor (Berthet et al., 2009; Bezzi and Volterra, 2011; Newman et al., 2011; Suzuki et al., 2011). Because of these effects, we hypothesized that lactate is an exercise factor that induces hippocampal $B d n f$ expression and mediates exercise's effects on learning and memory. In this work, we show that voluntary exercise induces lactate accumulation in the hippocampus, where it promotes learning and memory formation by inducing $B d n f$ expression through silent information regulator 1 (SIRT1)-dependent induction of the PGCla/FNDC5 pathway.

\section{Materials and Methods}

\section{Animal housing and lactate injections}

Adult male C57BL/6 mice were housed in cages and divided according to the experimental groups: saline or lactate receiving. The mice were provided with food and water ad libitum and maintained on a $12 \mathrm{~h} \mathrm{light/dark}$ cycle. Male mice were intraperitoneally injected with different lactate concentrations (117 or $180 \mathrm{mg} / \mathrm{kg}$ ) alone or in combination with the TRK inhibitor CEP701 (3 mg/kg) or with saline. Mice were killed 1 or $4 \mathrm{~h}$ after injection time; the brains were dissected on dry ice, and the hippocampi were collected and stored at $-80^{\circ} \mathrm{C}$ for later analysis. Animal care and use were in accordance with the guidelines set by the National
Institutes of Health and the Lebanese Ministry of Health and as approved by the Animal Care and Use Committee.

Exercise paradigm. Male mice were individually housed with food and water ad libitum and maintained on a $12 \mathrm{~h}$ light/dark cycle. They were divided into two groups: sedentary animals or exercising animals. The exercising animals were housed with free access to a running wheel. Animals were killed after $30 \mathrm{~d}$, and hippocampi were collected and immediately frozen on dry ice. Animal care and use were in accordance with the guidelines set by the National Institutes of Health and the Lebanese Ministry of Health. In the experiments that tested the effect of lactate transporter inhibition on exercise-induced hippocampal $B d n f$ expression, animals received intraperitoneal injections of ARC- 155858 ( $50 \mathrm{~nm} /$ mouse) once daily on exercise days $26-28$, and twice daily within $5 \mathrm{~h}$ time interval on days 29 and 30 . Animals were killed after $30 \mathrm{~d}$, and hippocampi were collected and immediately frozen on dry ice. In the experiments that tested the effect of lactate transporter inhibition on exercise-induced spatial learning, animals received intraperitoneal injections of ARC-155858 (50 nM/mouse) once daily on exercise days 26-30, and twice daily for the duration of the water maze test: Morris Water Maze (MWM).

Cell culture. Immature primary cortical, hippocampal, and mixed (cortical/hippocampal) neurons were obtained from C57BL/6 mice (embryonic day 17 [E17]) as previously described (Ratan et al., 1994a,b). Mature cortical neurons were maintained in Neurobasal media (Invitrogen) supplemented with B27, and Glutamax (Invitrogen).

Cell treatment. Primary neurons were isolated as described above, and 1 million cells were plated in six well plates. On day 6, cells were treated with different concentrations of lactate (Sigma-Aldrich) for 1 or $4 \mathrm{~h}$. Lactate was prepared as $0.62 \mathrm{~m}$ stock in PBS and used at a final concentration of $20 \mathrm{~mm}$. Sirtinol (Sigma-Aldrich) was prepared as $10 \mathrm{~mm}$ stock in DMSO and used at a final concentration of $50 \mu \mathrm{M}$.

$R N A$ extraction and RT-PCR. Total RNA was prepared from primary cortical neurons or hippocampi using the Rneasy Plus Mini RNA extraction kit (QIAGEN) or NucleoSpin RNA II Kit (Clontech) according to the manufacturer's protocol. Reverse transcription was performed using iScript cDNA Reverse transcription kit (Bio-rad) according to the manufacturer's protocol. Real-time PCRs were performed using standard PCR protocol, with SYBR Green dye (Bio-Rad).

Details of the primers used are as follows: primer sequence $\left(5^{\prime}-3^{\prime}\right)$ : Bdnf pI: forward, 5' -CAGGACAGCAAAGCCACAAT; reverse, 5' -GC CTTCATGCAACCGAAGTA; Sirt 1: forward, AAAGGAATTGGTTC ATTTATCAGAG; reverse, TTGTGGTTTTTCTTCCACACA; forward, 5'-CTCTCTGCTCCTCCCTGTTC; reverse, 5'-CCGACCTTCAC CATTTTGTC; Pgcla: forward, TGATGTGAATGACTTGGATACA GACA; reverse, GCTCATTGTTGTACTGGTTGGATATG; Fndc5: forward, ATGAAGGAGATGGGGAGGAA; reverse, GCGGCAGAA GAGAGCTATAACA; Arc: forward, 5'-TACCGTTAGCCCCTATGC CATC; reverse, $5^{\prime}$-TGATATTGCTGAGCCTCAACTG; Zif268: forward, 5'-TATGAGCACCTGACCACAGAGTCC; reverse, 5'-CGAGTCGTT TGGCTGGGATAAC

Protein extractions. Total cell proteins were prepared by lysing cells in RIPA-B (1\% Triton X-100, 1\% SDS, 50 mm Tris-Cl, pH 7.4, $500 \mathrm{~mm}$ $\mathrm{NaCl}$, and $1 \mathrm{~mm}$ EDTA) in the presence of protease inhibitors (SigmaAldrich), the proteasome inhibitor MG-132 (Sigma-Aldrich), and phosphatase inhibitors (Sigma-Aldrich) followed by benzonase nuclease (Sigma-Aldrich) digestion for $15 \mathrm{~min}$. Nuclear proteins were prepared by homogenizing and lysing hippocampi first in buffer A (10 mM HEPES, pH 7.9, $10 \mathrm{~mm} \mathrm{KCl}, 1.5 \mathrm{~mm} \mathrm{MgCl}_{2}, 0.34 \mathrm{~m}$ sucrose, $10 \%$ glycerol, $0.1 \%$ Triton X-100, 1 mM DTT, protease inhibitors, PMSF, MG132, and sodium orthovanadate). Next, nuclear proteins were extracted in buffer $B$ (3 mm EDTA, $0.2 \mathrm{~mm}$ EGTA, $0.3 \mathrm{~m} \mathrm{NaCl}, 1 \mathrm{~mm}$ DTT, protease inhibitors, MG132, and phosphatase inhibitors).

Lactate measurements. Hippocampal lactate levels were measured using the L-lactate assay kit (Abcam) according to the manufacturer's protocol.

Sirt1 activity measurements. Hippocampal Sirt1 activity was measured from nuclear lysates using the Universal SIRT Activity Assay Kit (Abcam) according to the manufacturer's protocol.

Western blot analysis. Samples were boiled in Laemmli buffer and electrophoresed on Bis-Tris 30\% acrylamide gels (Bio-Rad). Proteins were 
transferred to a PVDF membrane (Bio-Rad) using semidry TransBlot Turbo Transfer System (Bio-Rad). Nonspecific binding was inhibited by incubation in blocking buffer (BSA and TBS-Tween 20). Antibodies against Trkb (gift from Moses V. Chao), phospho-Trkb (gift from Moses V. Chao), BDNF (Santa Cruz Biotechnology), ARC (Abcam), ZIF268 (Abcam), PGCla (Abcam), FNDC5 (Abcam), and $\beta$-actin (SigmaAldrich) were diluted 1:1000, 1:1500, 1:1000, 1:1000, and 1:5000, respectively, in blocking buffer, and the membranes were incubated overnight at $4^{\circ} \mathrm{C}$. Secondary antibodies (Bio-Rad) were used at a 1:5000 dilution followed by incubation for $90 \mathrm{~min}$ at room temperature. Finally, proteins were detected by chemiluminescence on ChemiDoc (Bio-Rad) using Clarity Western ECL Substrate (Bio-Rad) or by SuperSignal West Femto Maximum Sensitivity Substrate (Pierce) for PGC1A and BDNF.

Sirtl short hairpin RNA (shRNA) knockdown

Five Sirt1(NM_019812) shRNA clones (Sigma-Aldrich) were used to knock down the expression of Sirt1 in mixed primary neuronal cultures as follows: TRCN0000327027 (CCGGGAGGGTAATCAAT ACCTGTTTCTCGAGAAACAGGTATTGATTACCCTCTTTTTG), TRCN0000327028 (CCGGCCTGAAAGAACTGTACCACAACTCG AGTTGTGGTACAGTTCTTTCAGGTTTTTG), TRCN0000306518 (CCGGCTAGACCAAAGAATGGTATTTCTCGAGAAATACCATTC TTTGGTCTAGTTTTTG), TRCN0000306512 (CCGGAGTGAGAC CAGTAGCACTAATCTCGAGATTAGTGCTACTGGTCTCACTTT TTTG), and TRCN0000326966 (CCGGGCCATGTTTGATATTGA GTATCTCGAGATACTCAATATCAAACATGGCTTTTTG).

The Sirtl shRNA clones and a Non-Target shRNA Control Vector (Sigma-Aldrich) were introduced into immature primary mixed neurons (E17) using the Amaxa mouse Neuron Nucleofector kit as directed by the manufacturer (Lonza Walkersville). On day 6, SIRT1 knockdown was confirmed by real-time RT-PCR.

\section{MWM}

C57BL/6 male mice (6 weeks) received intraperitoneal injections of saline or lactate and tested in an MWM after $4 \mathrm{~h}$. All water maze data were recorded using ANY-maze Video Tracking System. The MWM was used as previously described (Morris, 1984). Briefly, mice used visual cues placed on the borders of a swimming pool to reach a hidden platform and escape from the water. Learning was assessed across $5 \mathrm{~d}$. Before learning assessment, mice were introduced into the pool that contains clear water and a visible platform. This training allowed the mice to become familiar with the task. During the learning phase, white paint was added to the water and the platform was submerged. Each mouse was subjected to three trials from different starting points. Latency or the time required to reach the platform was recorded every day by the ANY-maze Video Tracking System. On the last day of the experiment, the platform was removed and each mouse was reintroduced into the water and the time spent in the quadrant that previously contained the platform (target quadrant) was recorded. $n=35,31$, and 34 for control, lactate 117 $\mathrm{mg} / \mathrm{kg}$, and $180 \mathrm{mg} / \mathrm{kg}$, respectively.

Statistical analysis

Unpaired $t$ test, one-way or two-way ANOVA followed by the Dunnett or Bonferroni post-tests, respectively, were used to measure statistical significance. $p<0.05$ was considered to be statistically significant. All graphs are presented as mean \pm SEM.

\section{Results}

Voluntary exercise promotes hippocampal $B d n f$ expression as well as learning and memory formation in a lactate-dependent manner

To assess whether exercise induces increases in hippocampal lactate concentrations, we subjected mice to a 30-d-long voluntary exercise protocol (Fig. 1A) (Wrann et al., 2013; Sleiman et al., 2016). Exercising mice in this paradigm have significantly higher hippocampal $B d n f$ expression levels ( $p=0.001$ for exercise vs control, one-way ANOVA) as measured by real-time RT-PCR (Fig. 1C) as well as BDNF signaling (Wrann et al., 2013; Sleiman et al., 2016). Interestingly, mice subjected to voluntary exercise

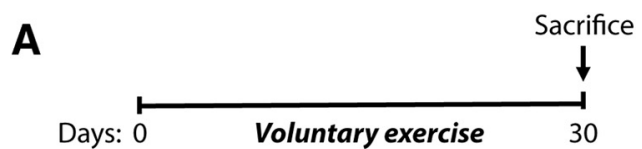

B
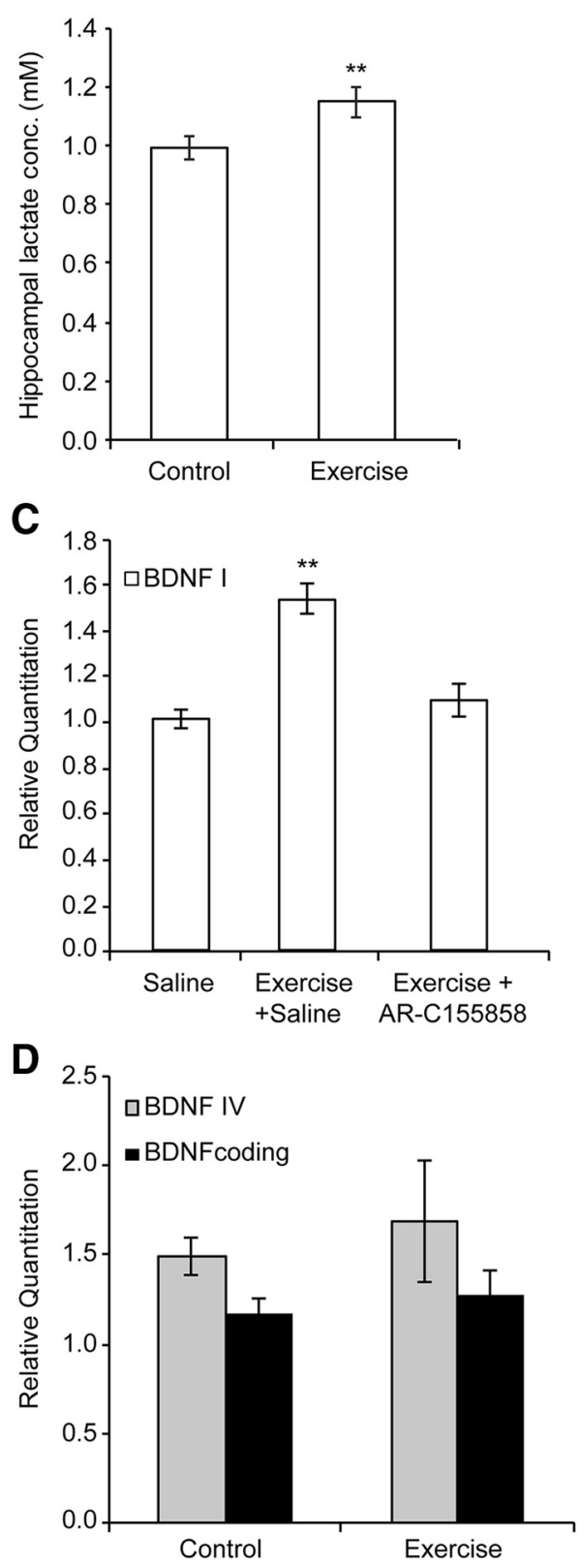

Figure 1. Lactate mediates in part the voluntary exercise-mediated induction of hippocampal $B d n f$ expression and promotion of learning. $A$, The exercise paradigm involves 4 weeks of voluntary exercise followed by animal death and hippocampal isolation. $\boldsymbol{B}$, Voluntary exercise for 4 weeks significantly increases hippocampal lactate levels. The number of hippocampi used for each group (control and exercise) is 10 and 9 , respectively. ${ }^{* *} p<0.01$ (unpaired $t$ test; $p=$ 0.0366 and df $=17)$. C, Voluntary exercise significantly induces $B d n f$ promoter I expression in the hippocampus as measured by real-time RT-PCR, whereas inhibiting the lactate MCT transporters by AR-C155858 ( $50 \mathrm{~nm} /$ mouse) abolishes this induction. The number of hippocampi used for each group (control, exercise, and exercise + AR-C155858) is 5, 2, and 4, respectively. ${ }^{* *} p<0.01$ (one-way ANOVA followed by Dunnett's multiple-comparison test; $p=0.001$ for exercise vs control and $p=0.4778$ for exercise + AR-C(155858 vs control). $\boldsymbol{D}$, Voluntary exercise does not induce $B d n f p l V$ or coding expression in the hippocampus as measured by real-time RT-PCR. 
showed a modest, yet significant, increase in hippocampal lactate levels compared with control mice $(p=0.0366$ and $\mathrm{df}=17$, unpaired $t$ test) (Fig. $1 B$ ). These data are consistent with previously reported increases in brain and hippocampal lactate levels after different exercise paradigms (Ide et al., 1999, 2000; Ferreira et al., 2007; Dienel, 2012). To assess whether voluntary exercise induces hippocampal $B d n f$ expression by increasing lactate levels, exercising mice received intraperitoneal injections of the lactate MCT1/2 inhibitor, AR-C155858 (Ovens et al., 2010). The Bdnf gene has multiple promoters that generate many transcripts through alternative splicing with a common coding exon (Pruunsild et al., 2011). We focused on the Bdnf gene promoter I (pI) because it is a neuronal activity-dependent (Tabuchi et al., 2002) and exercise-dependent promoter (Tong et al., 2001; Sleiman et al., 2016). As expected, exercising mice have significantly higher hippocampal Bdnf promoter I (Fig. 1C), but not promoter IV or coding (Fig. 1D) expression levels compared with control as measured by real-time RT-PCR. The increase in promoter I expression was abolished in exercising mice that received the lactate transporter inhibitor, AR-C155858 ( $p=0.001$ for exercise vs control and $p=0.4778$ for exercise $+\mathrm{AR}-\mathrm{C} 155858$ vs control; one-way ANOVA followed by Dunnett's post-test) (Fig. $1 C)$. These data demonstrate that lactate, which is released in the peripheral organs during voluntary exercise, crosses the BBB and accumulates in the hippocampus where it is important for exercise's effect on $B d n f$ induction.

\section{Intraperitoneal delivery of lactate induces $B d n f$ expression and signaling in the hippocampus}

To assess whether lactate, a metabolite that is increased in the blood by exercise (Smith et al., 1997; Ide et al., 1999, 2000; Ferreira et al., 2007; Meek et al., 2009; Dienel, 2012), directly enhances $B d n f$ gene expression in the hippocampus, we injected mice intraperitoneally with either saline or lactate (117 or 180 $\mathrm{mg} / \mathrm{kg}$ ). Animals were killed $1 \mathrm{~h}$ after the injections, and tissues were collected for analysis. The amount of lactate that was injected yields 13 or $20 \mathrm{~mm}$ lactate concentrations in the blood. These concentrations are consistent with lactate plasma levels reported after exercise. Indeed, exercise induces an increase in plasma lactate concentrations that can reach up to $30 \mathrm{~mm}$ (Dienel, 2012) as well as a concomitant increase in brain and hippocampal lactate concentrations (Ide et al., 1999, 2000; Ferreira et al., 2007; Dienel, 2012). The two concentrations we used yielded modest increases in hippocampal lactate levels (Fig. $2 \mathrm{~A}$ ) ( $p=0.003$ for lactate $117 \mathrm{mg} / \mathrm{kg}$ vs control; one-way ANOVA followed by Dunnett's post-test) very similar to the increases that were observed in the exercising mice (Fig. 1B). To determine the effects of lactate on $B d n f$ expression in the hippocampus, we performed real-time RT-PCR. Our results showed that, like exercise (Fig. 1C), lactate significantly induced $B d n f$ promoter I expression in the hippocampus $(p=0.0316$ for lactate $117 \mathrm{mg} / \mathrm{kg}$ vs control and $p=0.0564$ for lactate $180 \mathrm{mg} / \mathrm{kg}$ vs control, one-way ANOVA followed by Dunnett's post-test) (Fig. 2B), but not $B d n f$ promoter IV or coding expression (Fig. 2C). Western blot analysis of hippocampal tissue isolated from animals receiving lactate showed a significant increase in BDNF protein levels $(p=0.0438$, and $\mathrm{df}=9$ as measured by unpaired $t$ test) and TRKB phosphorylation compared with control mice $(p=0.000052$ and $\mathrm{df}=4$ as measured by unpaired $t$ test) (Fig. $2 D-F$ ) as well as an increase in the protein levels of the synaptic plasticity genes ARC and ZIF268 (ZIF268 $p=0.0196, \mathrm{df}=9$ for lactate $180 \mathrm{mg} / \mathrm{kg}$ vs control; ARC $p=0.0303, \mathrm{df}=7$ for lactate $180 \mathrm{mg} / \mathrm{kg}$ vs control as measured by one-way ANOVA followed by the Dunnett's post-test) (Fig.
$2 G, H)$. Together, the data are consistent with systemic delivery of lactate-activating, BDNF-signaling pathways in the hippocampus. Interestingly, inhibiting the MCT1/2 lactate transporters abolished the lactate-mediated induction of hippocampal $B d n f$ expression, emphasizing the importance of the ability of lactate to cross the $\mathrm{BBB}$ (Fig. 2I). Interestingly, the ability of lactate to induce $B d n f$ promoter I, but not promoter IV or coding expression, was not restricted to the hippocampus but was also observed in the cortex ( $p=0.0367, \mathrm{df}=6$ as measured by unpaired $t$ test $)$ (Fig. 3A). These results led us to test whether lactate-mediated induction of $B d n f$ expression is neuron-specific.

\section{Lactate induces $B d n f$ and synaptic plasticity gene expression in primary neurons}

To test whether lactate can induce the expression of $B d n f$ in neurons, we treated primary neuronal cultures with lactate for $1 \mathrm{~h}$, extracted neuronal RNA, and performed real time RT-PCR. We found that lactate significantly induced $B d n f$ promoter I expression in primary hippocampal ( $p=0.0073$ and $\mathrm{df}=9$ for lactate $20 \mathrm{~mm}$ vs control) (Fig. $3 A$ ) and cortical neuronal cultures $(p=$ 0.0014 and $\mathrm{df}=4$ for lactate $20 \mathrm{~mm}$ vs control; unpaired $t$ test) (Fig. $3 B$ ). In addition, lactate also induced the expression of synaptic plasticity genes, such as Arc and Zif268/Egr1 (for Arc, $p=$ 0.0014 and $\mathrm{df}=5$ for lactate $20 \mathrm{~mm}$ vs control and for Zif268, $p=$ 0.0039 and $\mathrm{df}=6$ for lactate $20 \mathrm{~mm}$ vs control) (Fig. $3 B$ ). We also confirmed that lactate increases the protein levels of BDNF ( $p=$ $0.0199, \mathrm{df}=4$ for lactate $20 \mathrm{~mm}$ vs control) (Fig. $3 D, F)$, ZIF268 $(p<0.0001, \mathrm{df}=2$ for lactate $20 \mathrm{~mm}$ vs control) (Fig. $3 D, G)$, and ARC ( $p=0.0483, \mathrm{df}=4$ for lactate $20 \mathrm{~mm}$ vs control) (Fig. $3 E, H)$. These results suggest that lactate can specifically induce the expression of synaptic plasticity genes in neuronal cells. For this reason, we decided to test whether the lactate-mediated induction of synaptic plasticity genes and particularly BDNF/TRKB signaling correlates with learning and memory phenotypes.

\section{Lactate enhances learning and memory formation}

To test whether the lactate-mediated induction of Bdnf expression is responsible for enhancing learning and spatial memory formation, we performed MWM experiments. The MWM is a spatial learning task that requires mice to locate a hidden platform in an opaque pool of water using visual cues. Acquisition of spatial learning in both control mice and lactate-injected mice was observed as reduced latency to reach the hidden platform by day 5 . Mice receiving lactate (117 and $180 \mathrm{mg} / \mathrm{kg}$ ) significantly outperformed the control mice (Fig. 4A). To assess reference memory, we performed a probe trial $24 \mathrm{~h}$ after the last training session (day 6), during which the platform was removed. As expected, lactate-injected mice showed significant enhancement of memory recall, as indicated by increased time spent in the target quadrant (Fig. $4 B$ ). In this test, we only observed significant enhancement with the $180 \mathrm{mg} / \mathrm{kg}$ lactate dose. Both control and lactate-injected mice had similar swim speed during training days 1-5 (Fig. 4C). These results show that lactate did not affect mouse motility or swimming ability. To assess whether the lactatemediated activation of the BDNF/TRKB pathway is responsible for enhanced memory formation, we injected mice with lactate $(180 \mathrm{mg} / \mathrm{kg}$ ) in combination with a TRK inhibitor, CEP701 (Obeid et al., 2014). Mice receiving this combinatorial treatment did not show a significant enhancement of memory recall (Fig. $4 D$ ). Together, our results are consistent with the model that exercise induces an increase in lactate concentration in the blood and hippocampus, which in turn mediates the induction of synaptic plasticity genes, such as $B d n f$, leading to enhanced spatial 
A
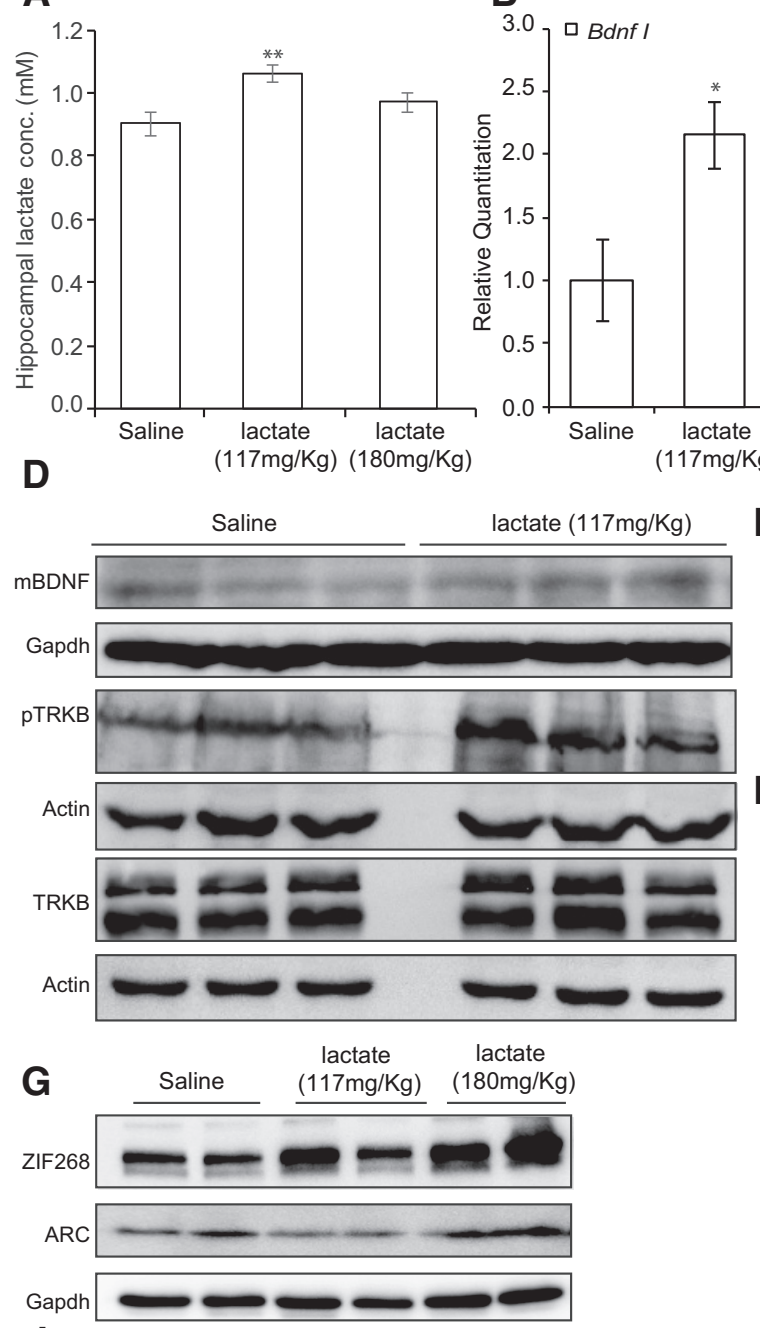

I

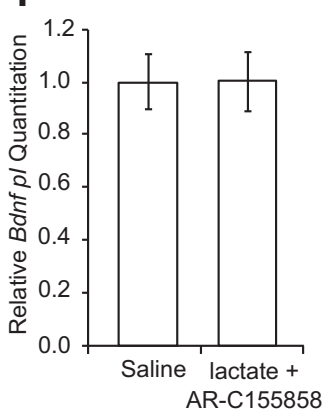

B

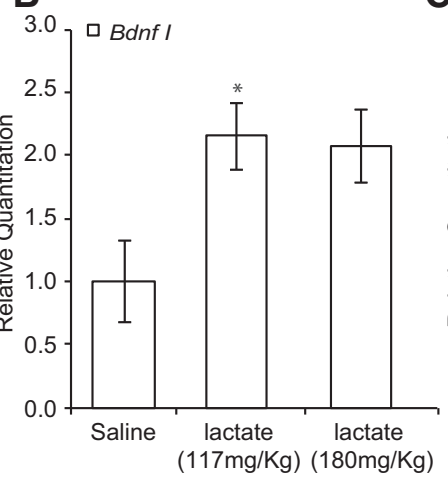

C

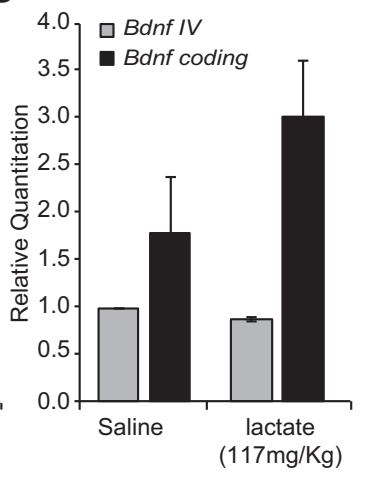

E

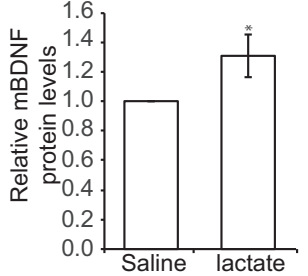

$\mathbf{F}$

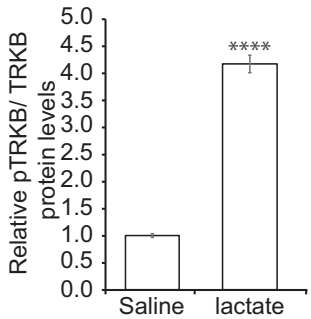

$\mathbf{H}_{3.5}$

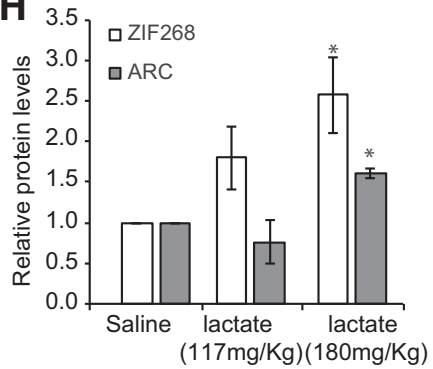

Figure 2. Peripheral delivery of lactate induces hippocampal Bdnf expression and signaling. $\boldsymbol{A}$, Intraperitoneal injections of lactate to reach equivalent levels to those reported in the blood after exercise lead to increases in hippocampal lactate. This increase is equivalent to the increase in hippocampal lactate observed after exercise. The number of hippocampi used for each group (control, lactate $117 \mathrm{mg} / \mathrm{kg}$, or lactate $180 \mathrm{mg} / \mathrm{kg}$ ) is 10,9 , and 7, respectively. ${ }^{* *} p<0.01$ (one-way ANOVA followed by the Dunnett's post-test; $p=0.003$ for lactate $117 \mathrm{mg} / \mathrm{kg}$ vs control). $\boldsymbol{B}$, Intraperitoneal injection of lactate ( 117 or $180 \mathrm{mg} / \mathrm{kg}$ ) similar to levels reported during exercise significantly induces hippocampal $B d n f p /$ expression levels as measured by real-time RT-PCR. The expression was analyzed from the hippocampi of 5 control mice, 5 mice receiving $117 \mathrm{mg} / \mathrm{kg}$ lactate, and 5 mice receiving $180 \mathrm{mg} / \mathrm{kg}$ lactate. ${ }^{*} p<$ 0.05 (one-way ANOVA followed by the Dunnett's multiple-comparison test; $p=0.0316$ for lactate $117 \mathrm{mg} / \mathrm{kg}$ vs control and $p=0.0564$ for lactate $180 \mathrm{mg} / \mathrm{kg}$ vs control). $C$, Intraperitoneal injection of lactate $(117 \mathrm{mg} / \mathrm{kg}$ ) does not induce hippocampal Bdnf p $/ V$ and coding expression levels as measured by real-time RT-PCR. The expression was analyzed from the hippocampi of 4 control mice and 4 mice receiving $117 \mathrm{mg} / \mathrm{kg}$ lactate. $D$, Representative Western blot image depicting the increase in BDNF protein levels and in phosphorylation in the BDNF receptor TRKBB (pTRKB) in the hippocampus of control animals compared with mice receiving $117 \mathrm{mg} / \mathrm{kg}$ of lactate. E, Quantification of the BDNF Western blot. ${ }^{*} p<0.05$ (unpaired $t$ test; $p=0.043$ and df $=4$ ). $F$, Quantification of the pTRKB Western blot. ${ }^{* * *} p<0.0001$ (unpaired $t$ test; $p=0.000052$ and df $=4$ ). $\boldsymbol{G}$, Representative Western blot image depicting the increase after $10 \mathrm{~min}$ in ZIF268 and ARC protein levels in the hippocampus of control animals compared with mice receiving $117 \mathrm{and} 180 \mathrm{mg} / \mathrm{kg}$ of lactate. $\boldsymbol{H}$, Quantification of the ZIF268 and ARC Western blots. ${ }^{*} p<0.05$ (one-way ANOVA followed by the Dunnett's multiple-comparison test; ZIF268, $p=0.0196, \mathrm{df}=9$ for lactate $180 \mathrm{mg} / \mathrm{kg}$ vs control; ARC, $p=0.0303, \mathrm{df}=7$ for lactate $180 \mathrm{mg} / \mathrm{kg}$ vs control). $I$, Intraperitoneal injection of lactate $(180 \mathrm{mg} / \mathrm{kg}$ ) along with the lactate MCT transporters AR-C 155858 (50 nm/mouse) did not induce hippocampal Bdnf p/ expression levels as measured by real-time RT-PCR. The expression was analyzed from the hippocampi of 5 control mice, 5 mice receiving $180 \mathrm{mg} / \mathrm{kg}$ lactate, and AR-C 155858 ( $50 \mathrm{~nm} /$ mouse). Significance was measured by unpaired $t$ test $(p=0.9910$ and $\mathrm{df}=8)$. 
A

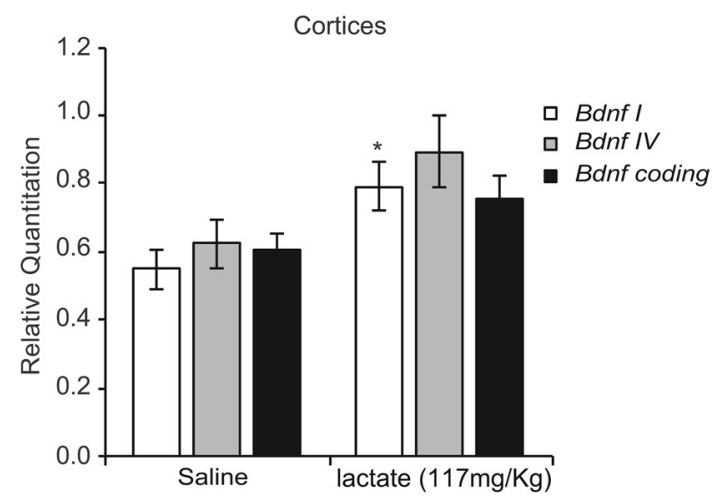

C

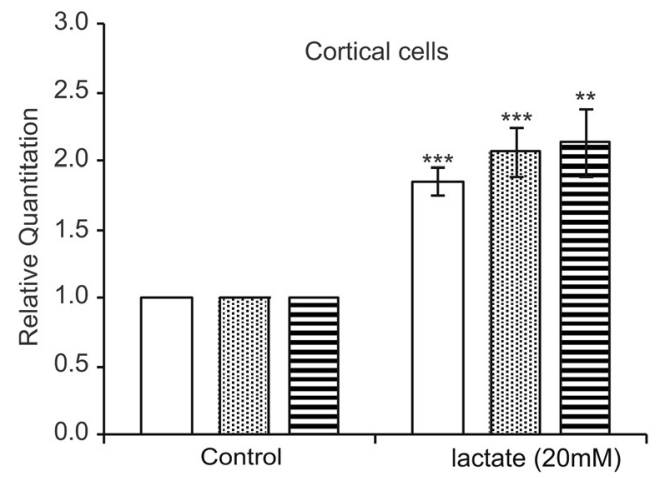

$\mathbf{F}$

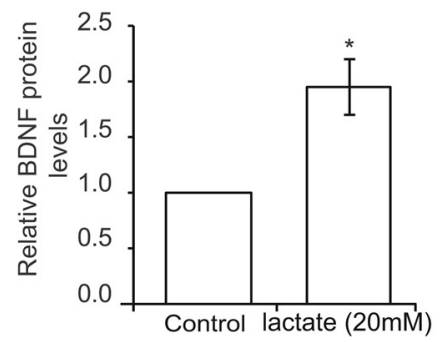

G

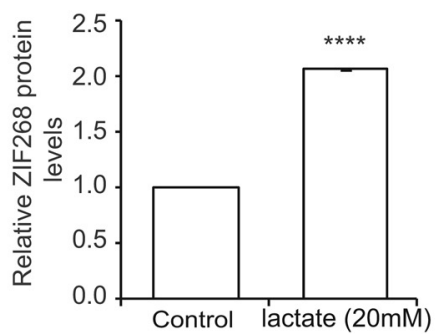

B

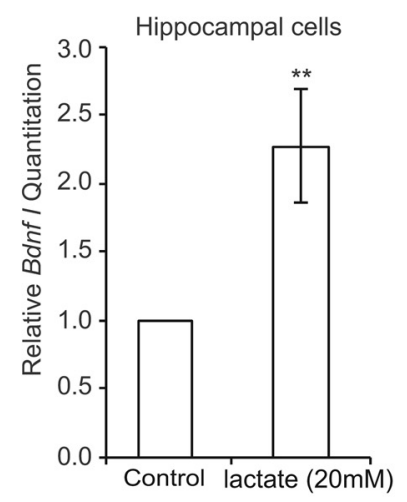

D

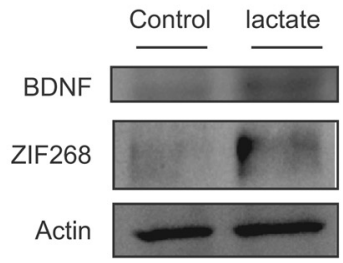

E

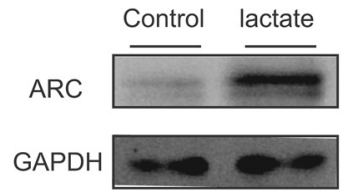

H

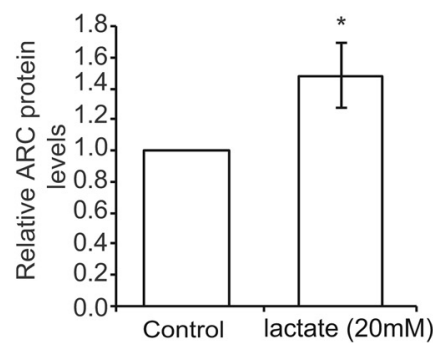

Figure 3. Lactate induces exercise-dependent $B d n f p l$ and activity-dependent gene expression in mouse primary neurons. $A$, Intraperitoneal injection of lactate $(117 \mathrm{mg} / \mathrm{kg})$ significantly induces cortical Bdnf pl but not $p / V$ or coding expression levels as measured by real-time RT-PCR. The expression was analyzed from the hippocampi of 4 control mice, 4 mice receiving $117 \mathrm{mg} / \mathrm{kg}$ lactate. ${ }^{*} p<0.05$ (unpaired t test; $p=0.036, \mathrm{df}=6$ for lactate $117 \mathrm{mg} / \mathrm{kg}$ vs control). $\boldsymbol{B}$, Lactate significantly induces $B d n f p /$ expression in primary hippocampal neurons as measured by real-time RT-PCR. ${ }^{* *} p<0.01$ (unpaired $t$ test $; p=0.0073$ and $\mathrm{df}=9$ for lactate $20 \mathrm{~mm} \mathrm{vs} \mathrm{control).} n=5$. Each replicate consisted of primary neurons obtained from different cultures and treated with fresh dilutions of the compounds for $1 \mathrm{~h}$. C, Lactate significantly induces Bdnf pl and activity-dependent gene (Arc and Zif268) expression in primary cortical neurons as measured by real-time RT-PCR. ${ }^{* *} p<0.01$ (unpaired $t$ test; $B d n f p l, p=0.0014$ and df $=4$ for lactate $20 \mathrm{~mm}$ vs control; $A r c, p=0.0014$ and df $=5$ for lactate $20 \mathrm{~mm}$ vs control; Zif $268, p=0.0039$ and df $=6$ for lactate $20 \mathrm{~mm}$ vs control). $n=4$. Each replicate consisted of primary neurons obtained from different cultures and treated with fresh dilutions of the compounds for $1 \mathrm{~h}$. $\boldsymbol{D}, \boldsymbol{E}$, Representative Western blot images depicting the lactate-mediated increase in BDNF, ZIF268, and ARC protein levels in mixed (cortical and hippocampal) primary neurons. F, Quantification of the BDNF Western blots. $p<<0.05$ (unpaired $t$ test: $p=0.0199, \mathrm{df}=4$ ). G, Quantification of the ZIF268 Western blots. ${ }^{*} p<0.05$ (unpaired $t$ test; $p<0.0001, \mathrm{df}=2$ ). $\boldsymbol{H}$, Quantification of the ARC Western blots. ${ }^{*} p<0.05$ (unpaired $t$ test; $p=$ $0.0483, \mathrm{df}=4) .{ }^{* * *} p<0.001 ;{ }^{* * *} p<0.0001$.

learning and memory retention. To verify whether indeed exercise-induced learning is lactate-dependent, we injected exercising mice with the lactate transporter inhibitor AR-C155858 and tested their ability to navigate the MWM. These mice exhibited significantly worsened learning curves compared with exercise mice injected with saline (Fig. 4E). We were next interested in elucidating the mechanism of action of lactate and specifically how lactate can mediate $B d n f$ induction in the hippocampus.

\section{Lactate induces $B d n f$ expression in an}

\section{SIRT1-dependent mechanism}

Exercise is accompanied by increases in energy requirements and changes in the levels of high energy molecules, such as ATP and the reduced coenzyme NADH. One class of enzymes whose activity is dependent on $\mathrm{NAD}^{+}$levels is the Sirtuins or Class III HDACs. This class of HDACs includes seven members (SIRT1-7) and is not only involved in the deacetylation of his- 
A

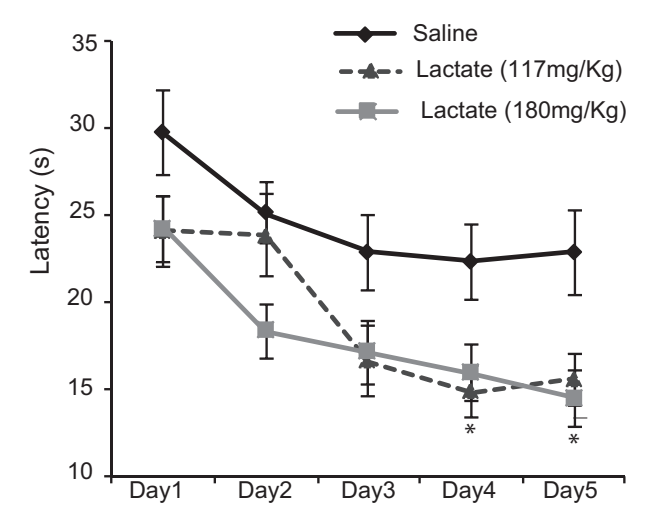

C

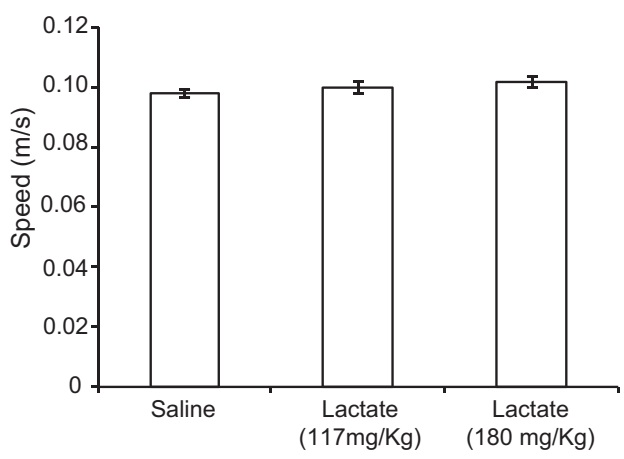

B

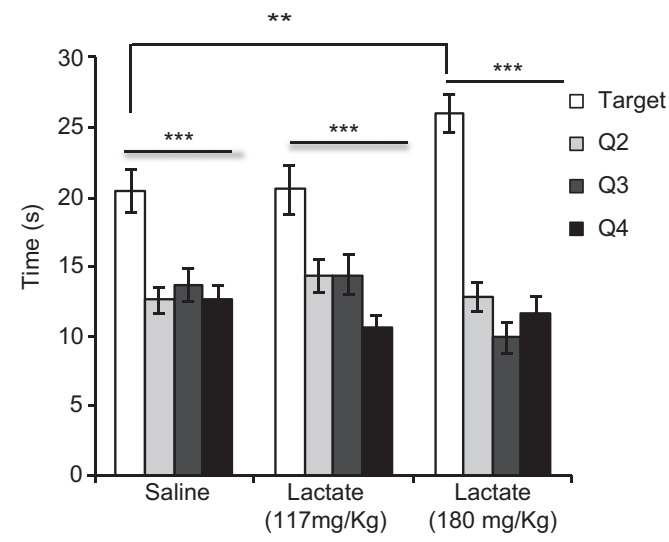

D

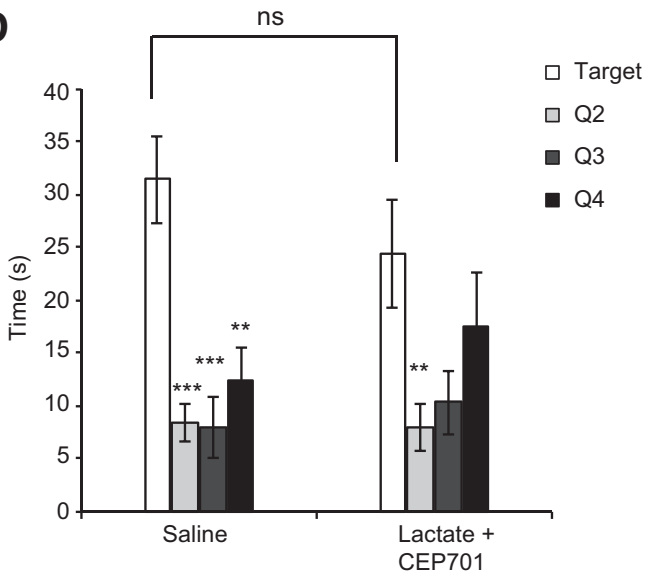

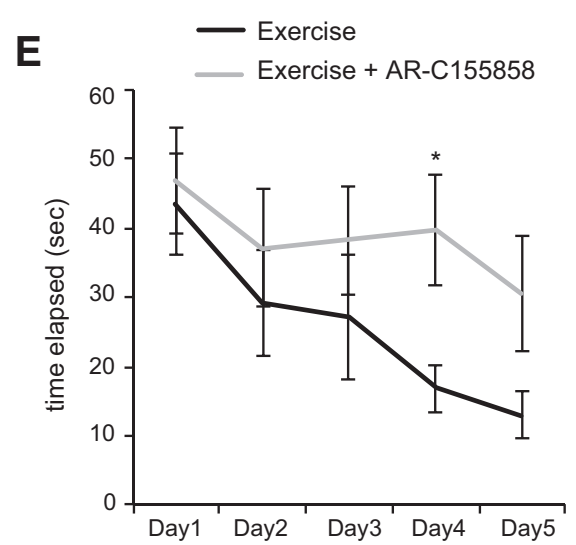

Figure 4. Peripheral delivery of lactate promotes learning and memory. $\boldsymbol{A}$, Animals were trained for $5 \mathrm{~d}$ in a spatial version of the MWM. Animals receiving intraperitoneal injections of lactate (118 and $180 \mathrm{mg} / \mathrm{kg}$ ) showed significantly reduced escape latency or the time (seconds) required to escape. Results are expressed as mean \pm SEM. ${ }^{*} p<0.05$ (two-way ANOVA followed by the Bonferroni post-test). $\boldsymbol{B}$, Animals receiving intraperitoneal injections of lactate $(180 \mathrm{mg} / \mathrm{kg})$ spent significantly more time in the target quadrant during a $60 \mathrm{~s}$ probe test performed $1 \mathrm{~d}$ after the last training session. Results are expressed as mean \pm SEM. Statistical significance between the target and the other three quadrants: ${ }^{* * *} p<0.0001$ (one-way ANOVA followed by Dunnett's post-test). Statistical significance between the target quadrants in saline and lactate-receiving mice: unpaired $t$ test ( $p=0.0056 \mathrm{and} \mathrm{df}=65$ ). $C$, The swimming speeds (meter/seconds) of the animals receiving intraperitoneal injections lactate were similar to those receiving saline, indicating that the effects observed in the training and probe test phase were not due to differences in motor behavior between the two groups of animals. $\boldsymbol{D}$, Animals receiving intraperitoneal injections of lactate (180 mg/kg) in combination with the TRK inhibitor, CEP 701 (3 mg/kg), did not spend significantly more time in the target quadrant compared with animals receiving intraperitoneal injections of saline during a $60 \mathrm{~s}$ probe test performed $1 \mathrm{~d}$ after the last training session. Results are expressed as mean \pm SEM. The number of animals used in each group is 5 . Statistical significance was measured by the unpaired $t$ test $(p=0.3117$, $\mathrm{df}=8)$. As expected, animals receiving saline spend significantly more time in the target quadrant. Statistical significance was measured by one-way ANOVA followed by the Dunnett's post-test; $p=0.0002$ for target versus Quadrant 2 ( $Q 2$ ) and 3 (Q3) and $p=0.0014$ for target versus Quadrant 4 (Q4). In contrast, animals receiving lactate and TRK inhibitor CEP701 did not spend significantly more time in the target quadrant compared with Q3 and Q4. One-way ANOVA followed by the Dunnett's post-test; $p=0.0295$ for target versus $Q 2, p=0.0652$ for target versus $Q 3$, and $p=0.4912$ for target versus $Q 4$. $E$, Inhibition of the lactate MCT transporters abolishes exercise-mediated spatial learning in the MWM paradigm. Exercise animals receiving intraperitoneal injections of the lactate MCT transporter inhibitor, AR-C155858 (50 $\mathrm{nm} /$ mouse) showed significantly increased escape latency or the time (seconds) required to escape compared with exercise animals receiving intraperitoneal injections of saline. Results are expressed as mean \pm SEM. ${ }^{*} p<0.05$ (two-way ANOVA followed by the Bonferroni post-test). ${ }^{* *} p<0.01$. 
A

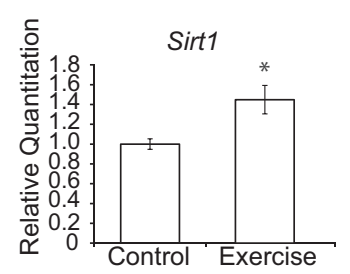

B

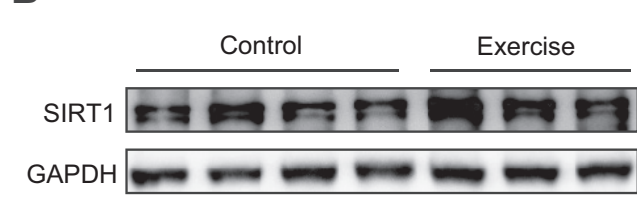

C
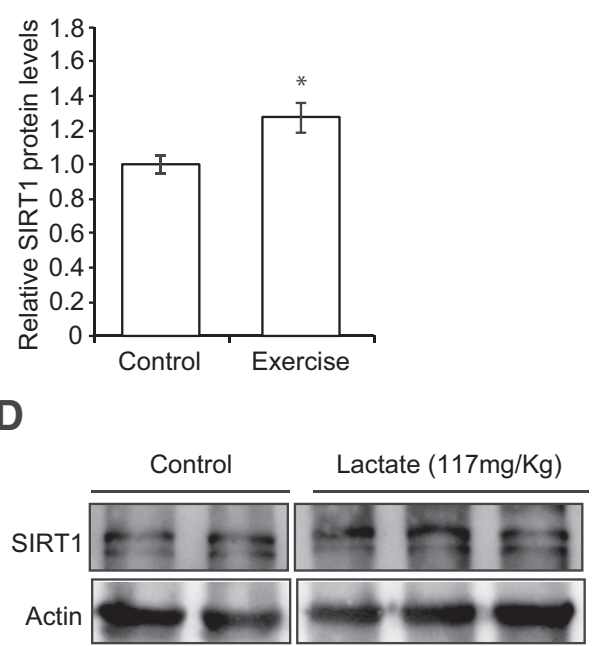

E

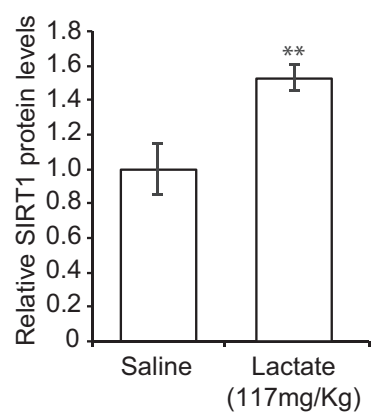

$\mathbf{F}$

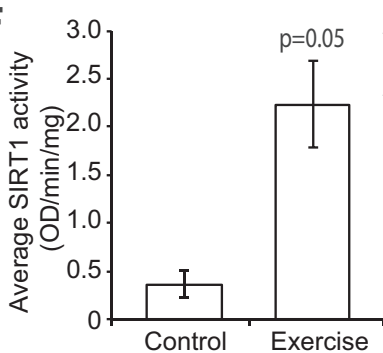

G

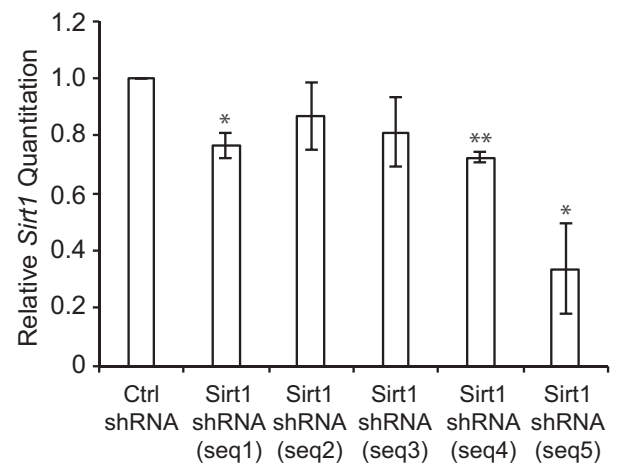

H
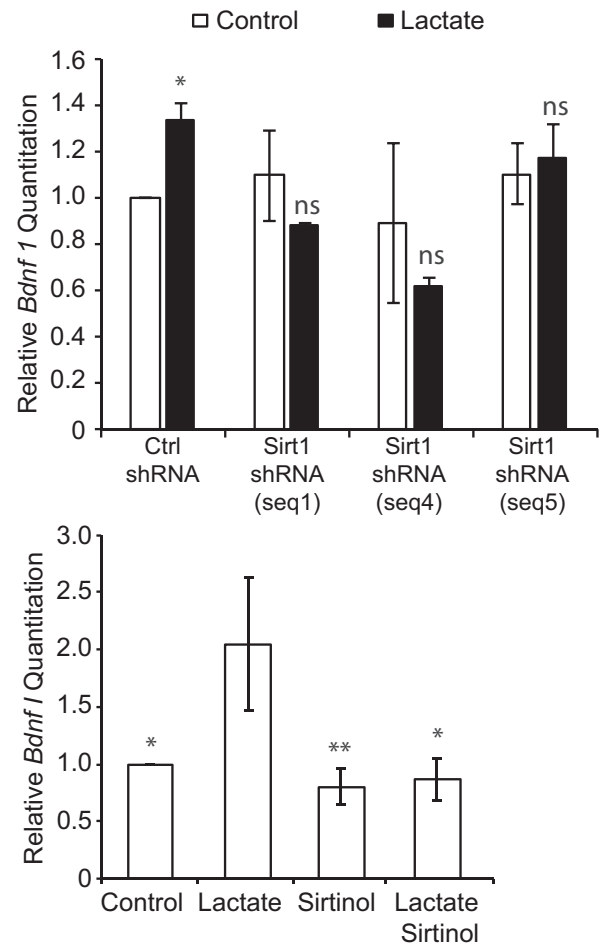

Figure 5. Lactate induces $B d n f$ expression in an SIRT1-dependent manner. $A$, Voluntary exercise for 4 weeks significantly induced Sirt1 expression in the hippocampus as measured by real-time RT-PCR. The number of animals used for each group (control and exercise) is 3 and 5 , respectively. ${ }^{*} p<0.05$ (unpaired $t$ test; $p=0.026$ and df $=6$ ). $\boldsymbol{B}$, Representative Western blot image depicting the increase in SIRT1 protein levels in the hippocampus of control animals compared with exercising mice. C, Quantification of the SIRT1 Western blot. For control and exercise, $n=4 .{ }^{*} p<0.05$ (unpaired $t$ test; $p=0.0456$ and df $=6$ ). $\boldsymbol{D}$, Representative Western blot image depicting the increase in SIRT1 protein levels in the hippocampus of mice receiving $117 \mathrm{mg} / \mathrm{kg}$ of lactate compared with mice receiving saline. $E$, Quantification of the SIRT1 Western blot. $n=5$ saline injections; $n=6$ lactate injections. ${ }^{* *} p<0.005$ (unpaired $t$ test; $p=0.0077$ and $\mathrm{df}=9)$. $\boldsymbol{F}$, Exercise and lactate $\left(117 \mathrm{mg} / \mathrm{kg}\right.$ ) induce SIRT1 activity in hippocampal nuclear extracts. ${ }^{*} p<0.05$ (unpaired $t$ test; exercise, $p=0.05$ and df $=3$; lactate, $p=0.059$ and $\mathrm{df}=3$ ). $\mathbf{G}$, Three shRNA sequences significantly decrease Sirt1 mRNA expression as measured by real-time RT-PCR. ${ }^{*} p<0.05$ (unpaired $t$ test; seq $1, p=0.0351$ and $\mathrm{df}=2$; seq 4, $p=0.0045$ and df $=2$; seq $5, p=0.05$ and df $=2$ ). $\boldsymbol{H}$, Sirtl knockdown abolishes the lactate-mediated increase in $B d n f p /$ expression. ${ }^{*} p<0.05$ (unpaired $t$ test; $p=0.0497$ and df $=2$ for (trl shRNA vs (trl shRNA + lactate $20 \mathrm{mm)}$. I, Sirtinol, a SIRT1 inhibitor, reversed the lactate-mediated induction of Bdnf pl expression in primary neurons as measured by real-time RT-PCR. For controls, lactate $(20 \mathrm{~mm})$, sirtinol $(50 \mu \mathrm{m})$, and lactate + sirtinol treatments, $n=6, n=4, n=6$, and $n=6$, respectively. Each replicate consisted of primary neurons obtained from different cultures and treated with fresh dilutions of the compounds for $4 \mathrm{~h}$. One-way ANOVA followed by the Dunnett's post-test: ${ }^{*} p<0.05 ;{ }^{* *} p<$ 0.01 ( $p=0.0273$ for control vs lactate, $p=0.0087$ for sirtinol vs lactate, and $p=0.0130$ for lactate + sirtinol vs lactate). 
A

C

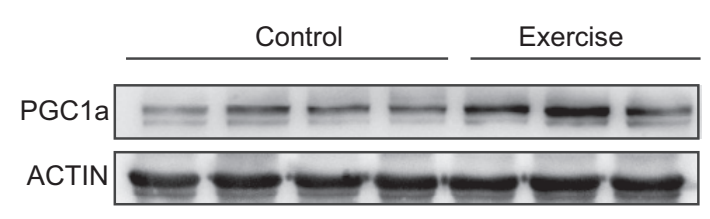

B

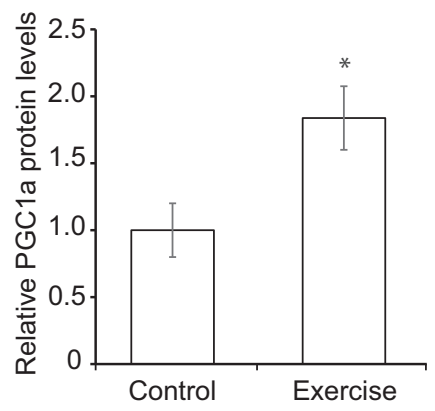

D
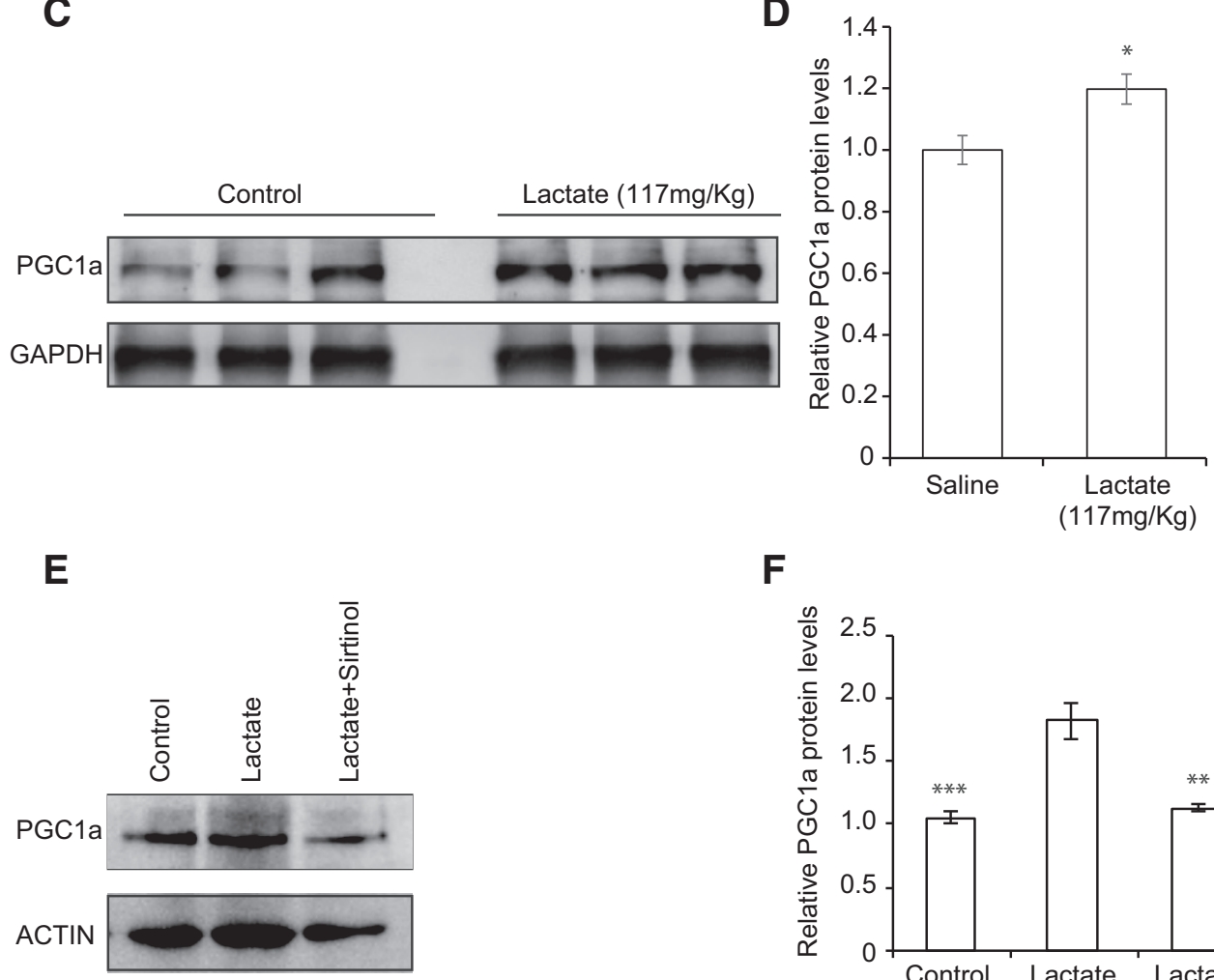

$\mathbf{F}$

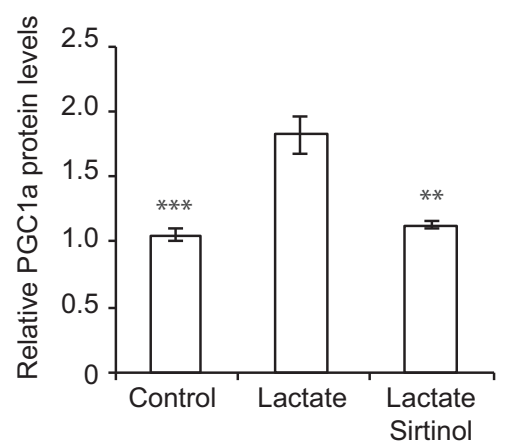

Figure 6. SIRT1 modulates Bdnf expression through induction of $\mathrm{PGC1}$ a protein levels. $A$, Representative Western blot image depicting the increase in $\mathrm{PGC}$ 1a protein levels in the hippocampus of control animals compared with exercising mice. $\boldsymbol{B}$, Quantification of the PGC1a Western blot. ${ }^{*} p<0.05$ (unpaired $t$ test; $p=0.05$, df $=4$ ). $C$, Representative Western blot image depicting the increase in PGC1a protein levels in the hippocampus of mice receiving $117 \mathrm{mg} / \mathrm{kg}$ of lactate compared with mice receiving saline. D, Quantification of the PGC1a Western blot. ${ }^{*} p<0.05$ (unpaired $t$ test; $p=0.0436$ and $\mathrm{df}=4) . \boldsymbol{E}$, Representative Western blot image depicting the increase in $\mathrm{PGC1}$ a protein levels in primary neurons treated with lactate $(20 \mathrm{~mm})$ and the reversal of this increase upon Sirt inhibitor (sirtinol $50 \mu \mathrm{M}$ ) cotreatment. These results suggest that the lactate-mediated induction of PGC1a protein levels is SIRT1-dependent. $\boldsymbol{F}$, Quantification of the PGC1a Western blot. ${ }^{*} p<0.05$ (one-way ANOVA followed by the Dunnett's post-test; $p=0.0007$ for control vs lactate, $p=0.002$ for lactate + sirtinol versus lactate). ${ }^{* *} p<0.01 ;{ }^{* * *} p<0.001$.

tones, but also many cellular proteins, including transcription factors. Among the members of this family, only SIRT1, SIRT6, and SIRT7 are resident nuclear proteins. Interestingly, voluntary exercise significantly induced the hippocampal expression of only Sirt 1 at both the mRNA ( $p=0.026$ and $\mathrm{df}=6$; unpaired $t$ test) (Fig. $5 A)$ and protein levels $(p=0.0456$ and $\mathrm{df}=6$; unpaired $t$ test). (Fig. $5 B, C$ ). Even though exercise induced Sirt7 mRNA as measured by real-time RT-PCR, it did not significantly induce SIRT7 protein levels (data not shown). Because lactate is produced and removed in reactions that directly affect the $\mathrm{NAD}^{+} / \mathrm{NADH}$ ratio, we decided to evaluate whether lactate also affected SIRT1 levels. We injected mice intraperitoneally with saline or lactate and examined the protein levels of SIRT1 in the hippocampus. We found that systemic delivery of lactate significantly increased the hippocampal levels of SIRT1 $(p=0.0077$ and $\mathrm{df}=9$; unpaired $t$ test) (Fig. 5D,E). Interestingly, like exercise, lactate also induced Sirt7 mRNA as measured by real-time RT-PCR, but did not significantly induce SIRT7 protein levels (data not shown). We next tested whether exercise and lactate affected SIRT1 deacetylase activity. We found that both exercise $(p=0.05$ and $\mathrm{df}=3)$ and intraperitoneal injections of lactate $(p=0.059$ and $\mathrm{df}=3)$ increased SIRT1 activity in hippocampal nuclear proteins (Fig. $5 F$ ). To evaluate whether the lactatemediated induction of $B d n f$ expression is SIRT1 dependent, we used shRNAs to knockdown Sirt1 expression as well as a SIRT1 inhibitor, sirtinol, and tested whether decreased SIRT1 levels and activity abolished the lactate-mediated $B d n f$ induction in primary neurons. Indeed, while lactate increased $B d n f$ promoter I mRNA expression in cells expressing the scrambled shRNA (Ctrl shRNA), it failed to increase Bdnf promoter I mRNA expression 
A

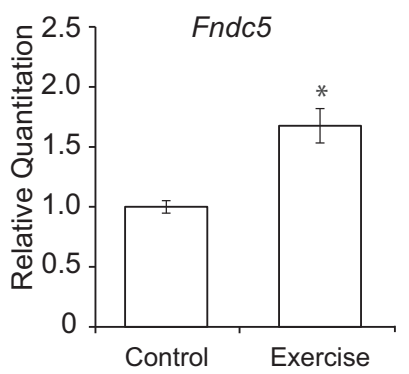

C

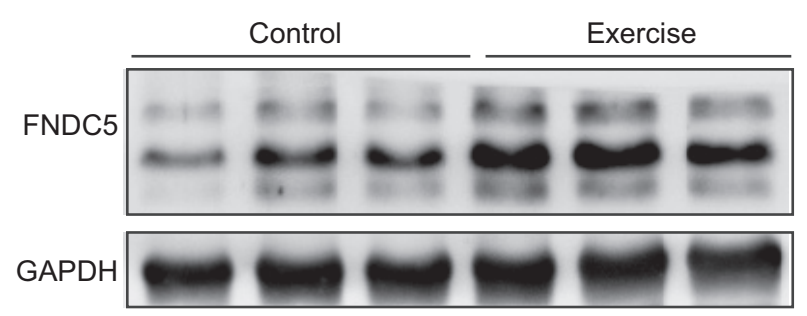

E
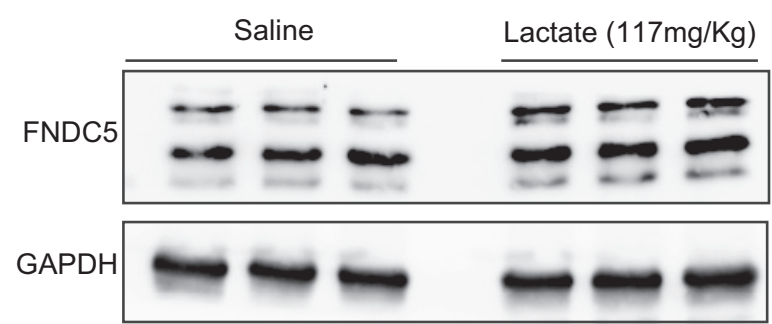

G

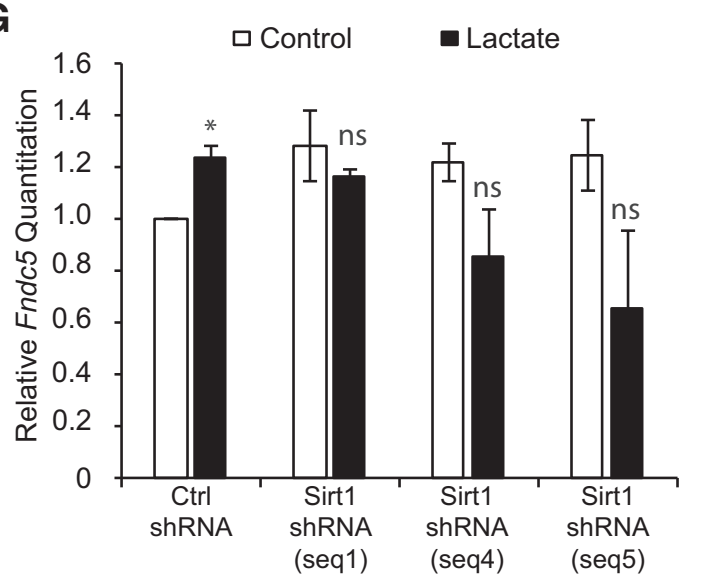

B

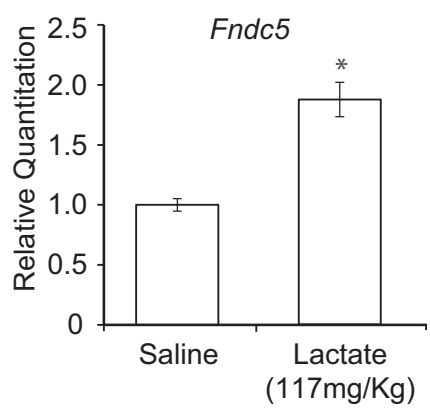

D

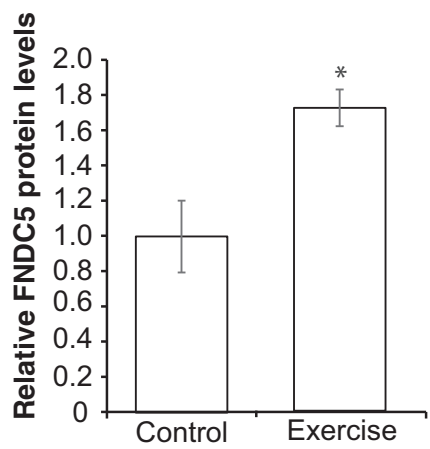

$\mathbf{F}$

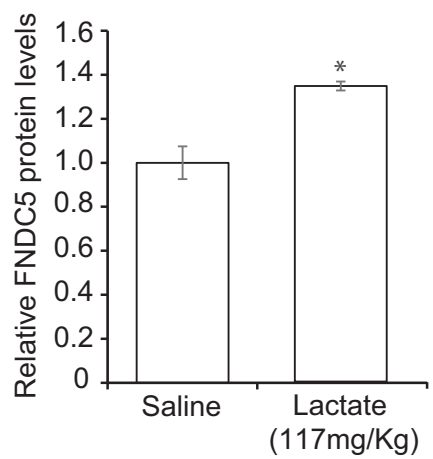

Figure 7. Lactate induces Fndc 5 levels, a PGC1a-dependent $B d n f$ inducer. $A$, Voluntary exercise for 4 weeks significantly induces $F n d c 5$ expression in the hippocampus as measured by real-time RT-PCR. The number of animals used for each group (control and exercise) is 3 and 4, respectively. ${ }^{*} p<0.05$ (unpaired $t$ test; $p=0.0183$ and df $=5$ ). $\boldsymbol{B}$, Intraperitoneal injections of lactate (117 $\mathrm{mg} / \mathrm{kg}$ ) significantly induced hippocampal Fndc 5 gene expression levels as measured by real-time RT-PCR. The number of animals used for each group is $5 .{ }^{*} p<0.05$ (unpaired $t$ test; $p=0.0152$ and df $=8$ ). $C$, Representative Western blot image depicting the increase in FNDC5 protein levels in the hippocampus of control animals compared with exercising mice. $D$, Quantification of the FNDC5 Western blot. ${ }^{*} p<0.05$ (unpaired $t$ test; $p=0.0347$ and $d f=4$ ). $\boldsymbol{E}$, Representative Western blot image depicting the increase in FNDC5 protein levels in the hippocampus of mice receiving $117 \mathrm{mg} / \mathrm{kg}$ of lactate compared with mice receiving saline. $\boldsymbol{F}$, Quantification of the FNDC5 Western blot. ${ }^{*} p<0.05$ (unpaired $t$ test; $p=0.0112$ and df $=4$ ). $\mathbf{G}$, Sirtl knockdown abolishes the lactate-mediated increase in Fndc5 mRNA expression. ${ }^{*} p<0.05$ (unpaired $t$ test; $p=0.0318$ and df $=2$ for (trl shRNA vs Ctrl shRNA + lactate $20 \mathrm{~mm}$ ). 


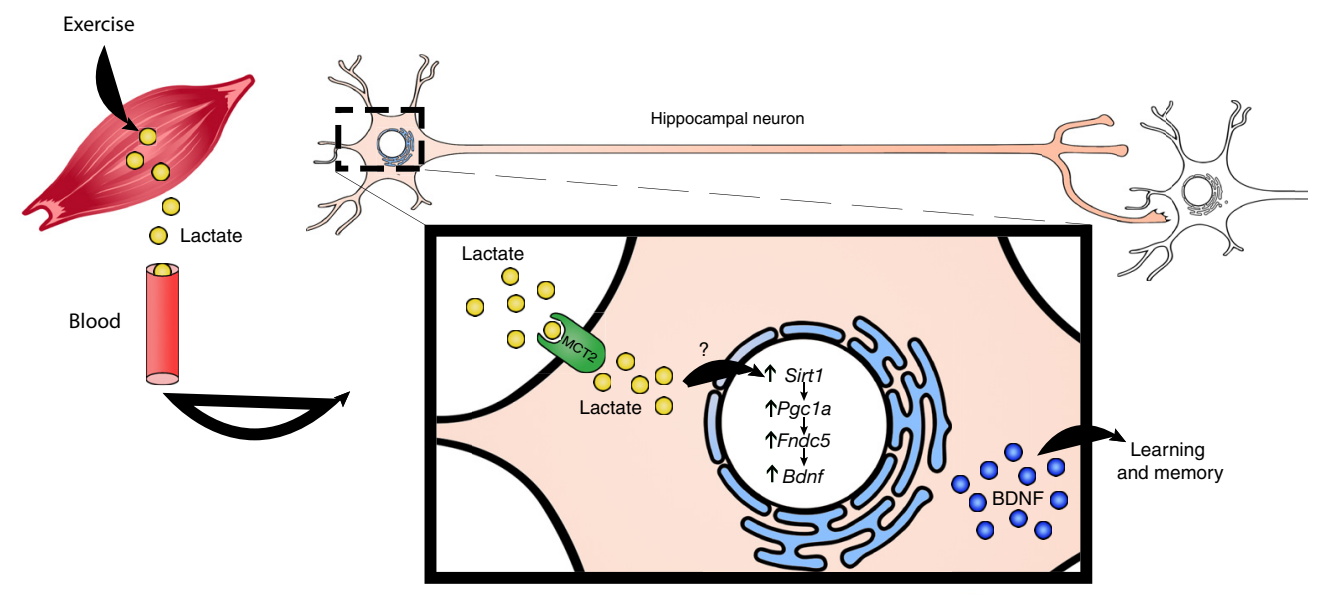

Figure 8. A proposed model by which exercise induces $B d n f$ expression in the hippocampus. Exercise induces lactate synthesis in the muscle. Lactate is transported through the circulation to the brain. In the hippocampus, lactate induces Bdnfexpression through SIRT1-dependent induction of PGC1a. PGC1a, in turn, coordinates the increase in Fndc5 expression, which is known to induce Bdnf expression. This induction mediates exercise's positive effects on memory, cognition, and synaptic transmission.

in cells expressing the Sirt1 shRNA (Fig. 5G,H). In addition, the lactate-induced $B d n f$ promoter I mRNA expression was lost upon cotreatment of neurons with lactate and sirtinol ( $p=0.0273$ for control vs lactate, $p=0.0087$ for sirtinol vs lactate and $p=0.0130$ for lactate + sirtinol vs lactate; one-way ANOVA followed by the Dunnett's post-test) (Fig. 5I). These results suggest that lactate activates $B d n f$ expression through an SIRT1-dependent mechanism.

Lactate induces $B d n f$ expression through SIRT1-dependent induction of PGC1a levels and in turn Fndc5 expression It was previously reported that voluntary exercise induces the expression of the transcriptional coactivator Pgcla and Erra mRNA in the hippocampus. PGCla and ERRa, in turn, coordinate to activate the hippocampal expression of the myokine Fndc5, which can induce Bdnf expression in the hippocampus (Wrann et al., 2013; Wrann, 2015). However, the mechanism by which the hippocampal induction of this pathway occurs in response to exercise has not been deciphered. We suspected that lactate could serve as the missing exercise factor. Indeed, one possible explanation for the effects of exercise is that it induces lactate accumulation in the hippocampus, which in turn activates SIRTs. SIRTs induce the PGC1a/FNDC5 pathway and lead to the induction of hippocampal $B d n f$ expression and enhanced learning and memory. To address this hypothesis, we first sought to confirm and assess whether voluntary exercise and intraperitoneal injections of lactate induce hippocampal PGCla protein levels. Indeed, Western blot analysis reveals that both voluntary exercise ( $p=0.05, \mathrm{df}=4$; unpaired $t$ test) and intraperitoneal injections of lactate $(p=0.0436$ and $\mathrm{df}=4$; unpaired $t$ test $)$ significantly increase hippocampal PGCla protein levels (Fig. $6 A-D$ ). To determine whether the lactate-mediated induction of $B d n f$ represents an SIRT1-dependent engagement of the hippocampal PGC1a/FNDC5 pathway, we treated primary neurons with lactate alone or combined with the sirtinol and assessed PGCla protein levels. Western blot analysis reveals that lactate induced PGCla protein levels, and this induction is lost upon combinatorial treatment of lactate and sirtinol $(p=0.0007$ for control vs lactate, $p=0.002$ for lactate + sirtinol versus lactate; one-way ANOVA followed by Dunnett's post-test). (Fig. 6E,F). These results suggest that both lactate-mediated induction of PGCla protein and BDNF expression are SIRT-dependent. Finally, it is well established that exercise-induced PGCla mediates hippocampal expression of FNDC5, which in turn activates Bdnf expression (Wrann et al., 2013; Wrann, 2015). We observed that, like exercise (mRNA: $p=0.0183$ and $\mathrm{df}=5$; protein: $p=0.0347$ and $\mathrm{df}=4$; unpaired test) (Fig. $7 A, C, D$ ), intraperitoneal injections of lactate induce hippocampal Fndc5 mRNA expression as measured by real-time RT-PCR $(p=0.0152$ and $\mathrm{df}=8$; unpaired $t$ test) (Fig. $7 B)$, and protein levels $(p=0.0112$ and $\mathrm{df}=4$; unpaired $t$ test) (Fig. $7 E, F$ ). Indeed, we found that, although lactate increased Fndc5 mRNA expression in cells expressing the scrambled shRNA (Ctrl shRNA), it failed to increase Bdnf promoter I mRNA expression in cells expressing the Sirt1 ShRNA (Fig. 7G). Together, these results are consistent with the model that exercise can promote learning and memory by inducing hippocampal $B d n f$ expression through lactate-mediated activation of the SIRT1/PGC1a/FNDC5 pathway (Fig. 8).

\section{Discussion}

These results provide a link between running exercise, lactate, SIRT1, and Bdnf gene expression. Previous work showed that lactate that is supplied to neurons by astrocytes can promote LTP (Skriver et al., 2014) and is important for memory formation (Newman et al., 2011; Suzuki et al., 2011; Steinman et al., 2016). Indeed, lactate activates the expression of synaptic plasticity genes by activating NMDA and ERK signaling cascades (Yang et al., 2014). In addition, lactate reduces glutamate-induced toxicity in the cortex (Ros et al., 2001) and protects against ischemic insults both in vitro (Berthet et al., 2012) and in middle cerebral artery occlusion stroke models (Berthet et al., 2009, 2012; Castillo et al., 2015). The neuroprotective effect of intravenous administration of lactate against ischemic damage suggests that lactate may serve as a potential inexpensive therapeutic strategy for stroke (Berthet et al., 2009, 2012). It is highly conceivable that lactate might act to increase the levels of BDNF, which can pro- 
mote learning and memory (Mu et al., 1999; Cirulli et al., 2004) as well as neuroprotection (Beck et al., 1994; Zuccato and Cattaneo, 2009; Zhao et al., 2017).

It has long been established that physical exercise induces hippocampal Bdnf expression (Neeper et al., 1995; Oliff et al., 1998; Tong et al., 2001; Cotman and Berchtold, 2002; Adlard and Cotman, 2004; Adlard et al., 2004, 2005a; Berchtold et al., 2005) and that this induction is necessary for cognitive processes, such as learning and memory (Vaynman et al., 2004; García-Mesa et al., 2014; Kim and Leem, 2016). We have only recently started deciphering the molecular pathways linking the exercise-induced metabolic changes in the liver and muscle to hippocampal Bdnf expression and increased cognition. It is clear, though, that the link involves multiple endogenous "exercise factors" that are released in the blood, can cross the BBB, and accumulate in the hippocampus where they engage signaling pathways that activate $B d n f$ expression. One previously identified exercise factor is $\mathrm{DBHB}$, a ketone body produced by the liver during exercise that accumulates in the hippocampus and induces Bdnf expression through HDAC inhibition (Sleiman et al., 2016). In this work, we identified lactate as a novel endogenous metabolite that links exercise to hippocampal $B d n f$ expression and to cognition. Lactate is not only supplied to neurons by astrocytes but is also released into the blood by the muscle during exercise. Lactate crosses BBB through MCTs and reaches multiple brain regions, including the hippocampus. During exercise, circulating lactate levels can reach $30 \mathrm{~mm}$, and hippocampal levels also significantly increase (Fig. 1) (Ide et al., 1999, 2000). Interestingly, exercise increases Mct2 levels in the hippocampus, and this increase is correlated with increases in BDNF and TrkB signaling (Takimoto and Hamada, 2014). This observation is consistent with the measured increases in lactate (Fig. 2) that uses the Mct2 to reach the hippocampus where it can mediate Bdnf expression (Fig. 2) (Sleiman et al., 2016). Indeed, lactate levels increase in the hippocampus after exercise (Fig. 1) (Ide et al., 1999, 2000). Like exercise, systemic delivery of lactate through intraperitoneal injections induces hippocampal $B d n f$ expression and signaling and can mediate learning and memory formation (Figs. 1-4). Our results are consistent with the finding that lactate released from exercising muscles mediates cerebral angiogenesis through the activation of the lactate receptor HCAR1 (Morland et al., 2017). Interestingly, we found that lactate activates the $\mathrm{NAD}^{+}$dependent histone deacetylase SIRT1 (Fig. 5), which in turn engage the previously identified hippocampal PGCla/FNDC5 pathway to induce $B d n f$ expression (Figs. 6, 7). Exercise has been shown to increase $B d n f$ levels through the induction of hippocampal expression of Fndc5, a PGCla and ERRa-dependent myokine (Wrann et al., 2013; Wrann, 2015). How exercise mediates the induction of PGCla and ERRa in the hippocampus has not been clearly established. Like exercise, lactate modulates the redox status of neurons by altering the $\mathrm{NAD}^{+} / \mathrm{NADH}$ ratio (Koltai et al., 2010), which leads to the activation of SIRT1. We observed that the exercise-mediated induction of hippocampal PGCla (Fig. 5); and in turn, FNDC5 (Fig. 6) expression is dependent on SIRT1 activity (Fig. 5).

A common theme that emerges from our data are the convergence of the action of the identified exercise factors on protein acetylation. DBHB acts as a HDAC2/3 inhibitor and mediates $B d n f$ induction by promoting histone acetylation at its promoter, whereas lactate activates SIRT1 that deacetylates the transcriptional coactivator PGCla. This promotes its activity (GerhartHines et al., 2007; Cantó et al., 2009) and allows it to induce gene expression. This is not surprising considering that histone acety- lation is a key regulator of memory consolidation in the hippocampus (Alarcón et al., 2004; Korzus et al., 2004; Levenson et al., 2004). Indeed, CREB binding protein (CBP) has been shown to be necessary for long-term memory formation (Guan et al., 2002; Korzus et al., 2004; Chen et al., 2010; Giralt et al., 2012). Introduction of a $\mathrm{CBP}$ activator that can cross the $\mathrm{BBB}$ promotes neurogenesis and increases memory duration (Chatterjee et al., 2013). In addition, CBP gene transfer rescues learning and memory deficits in an $\mathrm{AD}$ mouse model through the induction of BDNF (Caccamo et al., 2010). Moreover, pharmacological inhibition of HDACs promotes learning and memory formation (Levenson et al., 2004; Vecsey et al., 2007; Stefanko et al., 2009; Penney and Tsai, 2014). Indeed, how multiple HDAC isoforms affect learning and memory has been elucidated. For example, HDAC2, negatively regulates hippocampal-dependent memory (Guan et al., 2009; Yamakawa et al., 2017). Recently, it was found that the enzyme acetyl-CoA synthetase 2 (ACSS2) binds to promoters of neuronal activity and memory-related genes where it locally catalyzes the production of acetyl coenzyme A (Acetyl CoA) from acetate, coenzyme A (CoA), and ATP. The Acetyl group of acetyl CoA is transferred by HATs to the local histones, leading to unwinding of chromatin and activation of gene expression (Mews et al., 2017; Watson and Tsai, 2017). Because of the ability of exercise factors to modulate protein acetylation, it would be interesting to determine whether other metabolites, including acetyl CoA, which can affect protein acetylation, play important roles in the positive effects of exercise on learning and memory.

In this paper, we provide evidence that an endogenous molecule, lactate, that crosses the $\mathrm{BBB}$, is increased by exercise to enhance BDNF signaling in the hippocampus and in turn promote learning and memory (Fig. 8). These results support the hypothesis that the elusive factors that mediate the positive effects of exercise on the brain serve the dual purpose of an energy fuel and epigenetic modulators that mediate their effects by altering hippocampal gene expression. Continued identification of additional such factors is of relevance to people afflicted with neurodegenerative diseases or depression who are likely to benefit from the ability of exercise to stimulate BDNF. Interestingly, there is recent evidence the lactate can promote resilience to stress in chronic social defeat mouse models (N.K., R.E.-G., S.F.S., unpublished data) as well as serve as an antidepressant (Carrard et al., 2018).

\section{References}

Adlard PA, Cotman CW (2004) Voluntary exercise protects against stressinduced decreases in brain-derived neurotrophic factor protein expression. Neuroscience 124:985-992.

Adlard PA, Perreau VM, Engesser-Cesar C, Cotman CW (2004) The timecourse of induction of brain-derived neurotrophic factor mRNA and protein in the rat hippocampus following voluntary exercise. Neurosci Lett 363:43-48

Adlard PA, Perreau VM, Cotman CW (2005a) The exercise-induced expression of BDNF within the hippocampus varies across life-span. Neurobiol Aging 26:511-520.

Adlard PA, Perreau VM, Pop V, Cotman CW (2005b) Voluntary exercise decreases amyloid load in a transgenic model of Alzheimer's disease. J Neurosci 25:4217-4221.

Alarcón JM, Malleret G, Touzani K, Vronskaya S, Ishii S, Kandel ER, Barco A (2004) Chromatin acetylation, memory, and LTP are impaired in $\mathrm{CBP}^{+/-}$mice: a model for the cognitive deficit in Rubinstein-Taybi syndrome and its amelioration. Neuron 42:947-959.

Beck T, Lindholm D, Castrén E, Wree A (1994) Brain-derived neurotrophic factor protects against ischemic cell damage in rat hippocampus. J Cereb Blood Flow Metab 14:689-692.

Berchtold NC, Chinn G, Chou M, Kesslak JP, Cotman CW (2005) Exercise 
primes a molecular memory for brain-derived neurotrophic factor protein induction in the rat hippocampus. Neuroscience 133:853-861.

Berchtold NC, Castello N, Cotman CW (2010) Exercise and timedependent benefits to learning and memory. Neuroscience 167:588-597.

Berthet C, Lei H, Thevenet J, Gruetter R, Magistretti PJ, Hirt L (2009) Neuroprotective role of lactate after cerebral ischemia. J Cereb Blood Flow Metab 29:1780-1789.

Berthet C, Castillo X, Magistretti PJ, Hirt L (2012) New evidence of neuroprotection by lactate after transient focal cerebral ischaemia: extended benefit after intracerebroventricular injection and efficacy of intravenous administration. Cerebrovasc Dis 34:329-335.

Bezzi P, Volterra A (2011) Astrocytes: powering memory. Cell 144:644645.

Caccamo A, Maldonado MA, Bokov AF, Majumder S, Oddo S (2010) CBP gene transfer increases BDNF levels and ameliorates learning and memory deficits in a mouse model of Alzheimer's disease. Proc Natl Acad Sci U S A 107:22687-22692.

Cantó C, Gerhart-Hines Z, Feige JN, Lagouge M, Noriega L, Milne JC, Elliott PJ, Puigserver P, Auwerx J (2009) AMPK regulates energy expenditure by modulating $\mathrm{NAD}^{+}$metabolism and SIRT1 activity. Nature 458:1056-1060.

Carrard A, Elsayed M, Margineanu M, Boury-Jamot B, Fragnière L, Meylan EM, Petit JM, Fiumelli H, Magistretti PJ, Martin JL (2018) Peripheral administration of lactate produces antidepressant-like effects. Mol Psychiatry 23:488.

Castillo X, Rosafio K, Wyss MT, Drandarov K, Buck A, Pellerin L, Weber B, Hirt L (2015) A probable dual mode of action for both L- and D-lactate neuroprotection in cerebral ischemia. J Cereb Blood Flow Metab 35: 1561-1569.

Chatterjee S, Mizar P, Cassel R, Neidl R, Selvi BR, Mohankrishna DV, Vedamurthy BM, Schneider A, Bousiges O, Mathis C, Cassel JC, Eswaramoorthy M, Kundu TK, Boutillier AL (2013) A novel activator of CBP/p300 acetyltransferases promotes neurogenesis and extends memory duration in adult mice. J Neurosci 33:10698-10712.

Chen G, Zou X, Watanabe H, van Deursen JM, Shen J (2010) CREB binding protein is required for both short-term and long-term memory formation. J Neurosci 30:13066-13077.

Cirulli F, Berry A, Chiarotti F, Alleva E (2004) Intrahippocampal administration of BDNF in adult rats affects short-term behavioral plasticity in the Morris water maze and performance in the elevated plus-maze. Hippocampus 14:802-807.

Cotman CW, Berchtold NC (2002) Exercise: a behavioral intervention to enhance brain health and plasticity. Trends Neurosci 25:295-301.

Cotman CW, Berchtold NC, Christie LA (2007) Exercise builds brain health: key roles of growth factor cascades and inflammation. Trends Neurosci 30:464-472.

Dienel GA (2012) Brain lactate metabolism: the discoveries and the controversies. J Cereb Blood Flow Metab 32:1107-1138.

Duman CH, Schlesinger L, Russell DS, Duman RS (2008) Voluntary exercise produces antidepressant and anxiolytic behavioral effects in mice. Brain Res 1199:148-158.

E L, Lu J, Selfridge JE, Burns JM, Swerdlow RH (2013) Lactate administration reproduces specific brain and liver exercise-related changes. J Neurochem 127:91-100.

Ferreira JC, Rolim NP, Bartholomeu JB, Gobatto CA, Kokubun E, Brum PC (2007) Maximal lactate steady state in running mice: effect of exercise training. Clin Exp Pharmacol Physiol 34:760-765.

García-Mesa Y, Pareja-Galeano H, Bonet-Costa V, Revilla S, Gómez-Cabrera MC, Gambini J, Giménez-Llort L, Cristòfol R, Viña J, Sanfeliu C (2014) Physical exercise neuroprotects ovariectomized 3xTg-AD mice through BDNF mechanisms. Psychoneuroendocrinology 45:154-166.

Gerhart-Hines Z, Rodgers JT, Bare O, Lerin C, Kim SH, Mostoslavsky R, Alt FW, Wu Z, Puigserver P (2007) Metabolic control of muscle mitochondrial function and fatty acid oxidation through SIRT1/PGC-1alpha. EMBO J 26:1913-1923.

Giralt A, Puigdellívol M, Carretón O, Paoletti P, Valero J, Parra-Damas A, Saura CA, Alberch J, Ginés S (2012) Long-term memory deficits in Huntington's disease are associated with reduced CBP histone acetylase activity. Hum Mol Genet 21:1203-1216.

Guan JS, Haggarty SJ, Giacometti E, Dannenberg JH, Joseph N, Gao J, Nieland TJ, Zhou Y, Wang X, Mazitschek R, Bradner JE, DePinho RA, Jae- nisch R, Tsai LH (2009) HDAC2 negatively regulates memory formation and synaptic plasticity. Nature 459:55-60.

Guan Z, Giustetto M, Lomvardas S, Kim JH, Miniaci MC, Schwartz JH, Thanos D, Kandel ER (2002) Integration of long-term-memory-related synaptic plasticity involves bidirectional regulation of gene expression and chromatin structure. Cell 111:483-493.

Gupta VK, You Y, Gupta VB, Klistorner A, Graham SL (2013) TrkB receptor signalling: implications in neurodegenerative, psychiatric and proliferative disorders. Int J Mol Sci 14:10122-10142.

Ide K, Horn A, Secher NH (1999) Cerebral metabolic response to submaximal exercise. J Appl Physiol 87:1604-1608.

Ide K, Schmalbruch IK, Quistorff B, Horn A, Secher NH (2000) Lactate, glucose and $\mathrm{O}_{2}$ uptake in human brain during recovery from maximal exercise. J Physiol 522:159-164.

Kim DM, Leem YH (2016) Chronic stress-induced memory deficits are reversed by regular exercise via AMPK-mediated BDNF induction. Neuroscience 324:271-285.

Koltai E, Szabo Z, Atalay M, Boldogh I, Naito H, Goto S, Nyakas C, Radak Z (2010) Exercise alters SIRT1, SIRT6, NAD and NAMPT levels in skeletal muscle of aged rats. Mech Ageing Dev 131:21-28.

Korzus E, Rosenfeld MG, Mayford M (2004) CBP histone acetyltransferase activity is a critical component of memory consolidation. Neuron 42:961972.

Levenson JM, O'Riordan KJ, Brown KD, Trinh MA, Molfese DL, Sweatt JD (2004) Regulation of histone acetylation during memory formation in the hippocampus. J Biol Chem 279:40545-40559.

Meek TH, Lonquich BP, Hannon RM, Garland T Jr (2009) Endurance capacity of mice selectively bred for high voluntary wheel running. J Exp Biol 212:2908-2917.

Mews P, Donahue G, Drake AM, Luczak V, Abel T, Berger SL (2017) AcetylCoA synthetase regulates histone acetylation and hippocampal memory. Nature 546:381-386.

Mitre M, Mariga A, Chao MV (2017) Neurotrophin signalling: novel insights into mechanisms and pathophysiology. Clin Sci (Lond) 131:13-23.

Morland C, Andersson KA, Haugen ØP, Hadzic A, Kleppa L, Gille A, Rinholm JE, Palibrk V, Diget EH, Kennedy LH, Stølen T, Hennestad E, Moldestad O, Cai Y, Puchades M, Offermanns S, Vervaeke K, Bjørås M, Wisløff U, Storm-Mathisen J, et al. (2017) Exercise induces cerebral VEGF and angiogenesis via the lactate receptor HCAR1. Nat Commun 8:15557.

Morris R (1984) Developments of a water-maze procedure for studying spatial learning in the rat. J Neurosci Methods 11:47-60.

Mu JS, Li WP, Yao ZB, Zhou XF (1999) Deprivation of endogenous brainderived neurotrophic factor results in impairment of spatial learning and memory in adult rats. Brain Res 835:259-265.

Neeper SA, Gómez-Pinilla F, Choi J, Cotman C (1995) Exercise and brain neurotrophins. Nature 373:109.

Newman LA, Korol DL, Gold PE (2011) Lactate produced by glycogenolysis in astrocytes regulates memory processing. PLoS One 6:e28427.

Nichol KE, Parachikova AI, Cotman CW (2007) Three weeks of running wheel exposure improves cognitive performance in the aged $\mathrm{Tg} 2576$ mouse. Behav Brain Res 184:124-132.

Obeid M, Rosenberg EC, Klein PM, Jensen FE (2014) Lestaurtinib (CEP701) attenuates "second hit" kainic acid-induced seizures following early life hypoxic seizures. Epilepsy Res 108:806-810.

Oliff HS, Berchtold NC, Isackson P, Cotman CW (1998) Exercise-induced regulation of brain-derived neurotrophic factor (BDNF) transcripts in the rat hippocampus. Brain Res Mol Brain Res 61:147-153.

Ovens MJ, Davies AJ, Wilson MC, Murray CM, Halestrap AP (2010) ARC155858 is a potent inhibitor of monocarboxylate transporters MCT1 and MCT2 that binds to an intracellular site involving transmembrane helices 7-10. Biochem J 425:523-530.

Parrini M, Ghezzi D, Deidda G, Medrihan L, Castroflorio E, Alberti M, Baldelli P, Cancedda L, Contestabile A (2017) Aerobic exercise and a BDNF-mimetic therapy rescue learning and memory in a mouse model of down syndrome. Sci Rep 7:16825.

Penney J, Tsai LH (2014) Histone deacetylases in memory and cognition. Sci Signal 7:re12.

Pierre K, Pellerin L (2005) Monocarboxylate transporters in the central nervous system: distribution, regulation and function. J Neurochem 94:1-14.

Pruunsild P, Sepp M, Orav E, Koppel I, Timmusk T (2011) Identification of cis-elements and transcription factors regulating neuronal activitydependent transcription of human BDNF gene. J Neurosci 31:3295-3308. 
Quistorff B, Secher NH, Van Lieshout JJ (2008) Lactate fuels the human brain during exercise. FASEB J 22:3443-3449.

Ratan RR, Murphy TH, Baraban JM (1994a) Macromolecular synthesis inhibitors prevent oxidative stress-induced apoptosis in embryonic cortical neurons by shunting cysteine from protein synthesis to glutathione. J Neurosci 14:4385-4392.

Ratan RR, Murphy TH, Baraban JM (1994b) Oxidative stress induces apoptosis in embryonic cortical neurons. J Neurochem 62:376-379.

Real CC, Ferreira AF, Chaves-Kirsten GP, Torrão AS, Pires RS, Britto LR (2013) BDNF receptor blockade hinders the beneficial effects of exercise in a rat model of Parkinson's disease. Neuroscience 237:118-129.

Ros J, Pecinska N, Alessandri B, Landolt H, Fillenz M (2001) Lactate reduces glutamate-induced neurotoxicity in rat cortex. J Neurosci Res 66:790794.

Russo-Neustadt AA, Beard RC, Huang YM, Cotman CW (2000) Physical activity and antidepressant treatment potentiate the expression of specific brain-derived neurotrophic factor transcripts in the rat hippocampus. Neuroscience 101:305-312.

Skriver K, Roig M, Lundbye-Jensen J, Pingel J, Helge JW, Kiens B, Nielsen JB (2014) Acute exercise improves motor memory: exploring potential biomarkers. Neurobiol Learn Mem 116:46-58.

Sleiman SF, Henry J, Al-Haddad R, El Hayek L, Abou Haidar E, Stringer T, Ulja D, Karuppagounder SS, Holson EB, Ratan RR, Ninan I, Chao MV (2016) Exercise promotes the expression of brain derived neurotrophic factor (BDNF) through the action of the ketone body beta-hydroxybutyrate. Elife 5:e15092.

Smith EW, Skelton MS, Kremer DE, Pascoe DD, Gladden LB (1997) Lactate distribution in the blood during progressive exercise. Med Sci Sports Exerc 29:654-660.

Stefanko DP, Barrett RM, Ly AR, Reolon GK, Wood MA (2009) Modulation of long-term memory for object recognition via HDAC inhibition. Proc Natl Acad Sci U S A 106:9447-9452.

Steinman MQ, Gao V, Alberini CM (2016) The role of lactate-mediated metabolic coupling between astrocytes and neurons in long-term memory formation. Front Integr Neurosci 10:10.

Suzuki A, Stern SA, Bozdagi O, Huntley GW, Walker RH, Magistretti PJ, Alberini CM (2011) Astrocyte-neuron lactate transport is required for long-term memory formation. Cell 144:810-823.

Tabuchi A, Sakaya H, Kisukeda T, Fushiki H, Tsuda M (2002) Involvement of an upstream stimulatory factor as well as cAMP-responsive elementbinding protein in the activation of brain-derived neurotrophic factor gene promoter I. J Biol Chem 277:35920-35931.

Tajiri N, Yasuhara T, Shingo T, Kondo A, Yuan W, Kadota T, Wang F, Baba T, Tayra JT, Morimoto T, Jing M, Kikuchi Y, Kuramoto S, Agari T, Miyoshi
Y, Fujino H, Obata F, Takeda I, Furuta T, Date I (2010) Exercise exerts neuroprotective effects on Parkinson's disease model of rats. Brain Res 1310:200-207.

Takimoto M, Hamada T (2014) Acute exercise increases brain regionspecific expression of MCT1, MCT2, MCT4, GLUT1, and COX IV proteins. J Appl Physiol 116:1238-1250.

Tong L, Shen H, Perreau VM, Balazs R, Cotman CW (2001) Effects of exercise on gene-expression profile in the rat hippocampus. Neurobiol Dis 8:1046-1056.

van Praag H, Christie BR, Sejnowski TJ, Gage FH (1999) Running enhances neurogenesis, learning, and long-term potentiation in mice. Proc Natl Acad Sci U S A 96:13427-13431.

Vaynman S, Ying Z, Gomez-Pinilla F (2004) Hippocampal BDNF mediates the efficacy of exercise on synaptic plasticity and cognition. Eur J Neurosci 20:2580-2590.

Vaynman S, Ying Z, Yin D, Gomez-Pinilla F (2006) Exercise differentially regulates synaptic proteins associated to the function of BDNF. Brain Res 1070:124-130.

Vecsey CG, Hawk JD, Lattal KM, Stein JM, Fabian SA, Attner MA, Cabrera SM, McDonough CB, Brindle PK, Abel T, Wood MA (2007) Histone deacetylase inhibitors enhance memory and synaptic plasticity via CREB: CBP-dependent transcriptional activation. J Neurosci 27:6128-6140.

Watson LA, Tsai LH (2017) Molecular biology: local metabolites linked to memory. Nature 546:361-362.

Wrann CD (2015) FNDC5/irisin: their role in the nervous system and as a mediator for beneficial effects of exercise on the brain. Brain Plast $1: 55-61$.

Wrann CD, White JP, Salogiannnis J, Laznik-Bogoslavski D, Wu J, Ma D, Lin JD, Greenberg ME, Spiegelman BM (2013) Exercise induces hippocampal BDNF through a PGC-1alpha/FNDC5 pathway. Cell Metab 18: 649-659.

Yamakawa H, Cheng J, Penney J, Gao F, Rueda R, Wang J, Yamakawa S, Kritskiy O, Gjoneska E, Tsai LH (2017) The transcription factor Sp3 cooperates with HDAC2 to regulate synaptic function and plasticity in neurons. Cell Rep 20:1319-1334

Yang J, Ruchti E, Petit JM, Jourdain P, Grenningloh G, Allaman I, Magistretti PJ (2014) Lactate promotes plasticity gene expression by potentiating NMDA signaling in neurons. Proc Natl Acad Sci U S A 111:12228-12233.

Zhao H, Alam A, San CY, Eguchi S, Chen Q, Lian Q, Ma D (2017) Molecular mechanisms of brain-derived neurotrophic factor in neuro-protection: recent developments. Brain Res 1665:1-21.

Zuccato C, Cattaneo E (2009) Brain-derived neurotrophic factor in neurodegenerative diseases. Nat Rev Neurol 5:311-322. 